\title{
WestVirginiaUniversity
}

THE RESEARCH REPOSITORY @ WVU

Graduate Theses, Dissertations, and Problem Reports

2018

\section{Choice Dynamics in Concurrent Ratio Schedules of Reinforcement}

\author{
Daniel Bell-Garrison
}

Follow this and additional works at: https://researchrepository.wvu.edu/etd

\section{Recommended Citation}

Bell-Garrison, Daniel, "Choice Dynamics in Concurrent Ratio Schedules of Reinforcement" (2018).

Graduate Theses, Dissertations, and Problem Reports. 5181.

https://researchrepository.wvu.edu/etd/5181

This Dissertation is protected by copyright and/or related rights. It has been brought to you by the The Research Repository @ WVU with permission from the rights-holder(s). You are free to use this Dissertation in any way that is permitted by the copyright and related rights legislation that applies to your use. For other uses you must obtain permission from the rights-holder(s) directly, unless additional rights are indicated by a Creative Commons license in the record and/ or on the work itself. This Dissertation has been accepted for inclusion in WVU Graduate Theses, Dissertations, and Problem Reports collection by an authorized administrator of The Research Repository @ WVU.

For more information, please contact researchrepository@mail.wvu.edu. 
Choice Dynamics in Concurrent Ratio Schedules of Reinforcement

\title{
Daniel Bell-Garrison
}

\author{
Dissertation submitted \\ to the Eberly College of Arts and Sciences \\ at West Virginia University
}

in partial fulfillment of the requirements for the degree of

Doctor of philosophy in

Psychology with Behavior Analysis emphasis

Andy Lattal, Ph.D., Chair

Michael Perone, Ph.D.

Claire St. Peter, Ph.D.

Cole Vonder Haar, Ph.D.

Dwight Harshbarger, Ph.D.

Department of Psychology

Morgantown, West Virginia

2018

Keywords: Choice; Concurrent Schedules; Ratio Schedules; Pigeons; Matching Law

Copyright 2018 Daniel Bell-Garrison 


\section{ABSTRACT \\ Choice Dynamics in Concurrent Ratio Schedules of Reinforcement}

\section{Daniel Bell-Garrison}

Roughly 50 years of research has demonstrated that choice changes as a function of the amount of reinforcement available from two concurrently available schedules of reinforcement, and this function has been labeled the generalized matching law. The matching law, however, historically only accounts for choice between two variable-interval schedules of reinforcement. If the matching law is to be a general perspective for how organisms allocate behavior amongst several alternatives, then it ought to account for behavior when reinforcers depend on work requirements in addition to time requirements. To study these contexts, the present experiments employed concurrent ratio schedules that were programmed nonindependently. As such, responses to one ratio schedule simultaneously incremented the response counter for both schedules. The probability of reinforcement increased on both schedules as responses were allocated to either schedule. In Experiment 1, response allocation of pigeons was assessed when three lengths of changeover delays ( $0 \mathrm{~s}, 2.5 \mathrm{~s}$, and $10 \mathrm{~s})$ were in effect. Experiment 2 compared choice in concurrent variable-ratio and fixed-ratio schedules. Experiment 3 controlled the number of reinforcers delivered to two concurrently-available variable-ratio schedules. When concurrent variable-ratio schedules were in effect, the matching law described choice well in all three experiments. Choice on concurrent fixed-ratio schedules was inconsistent across pigeons. The main variable controlling response allocation in all experiments was the distribution of reinforcement. By controlling the number of reinforcers delivered to each schedule, choice can be brought under precise control even when ratio schedules are in effect. These results support extensions of the generalized matching law to contexts in which reinforcers are contingent on response requirements rather than time requirements. 


\section{Table of Contents}

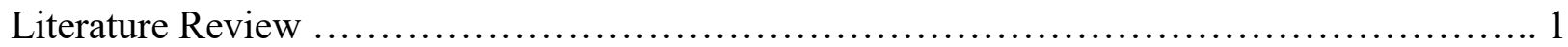

Statement of the Problem......................................................... 11

Experiment 1 Method................................................................ 14

Experiment 1 Results............................................................. 17

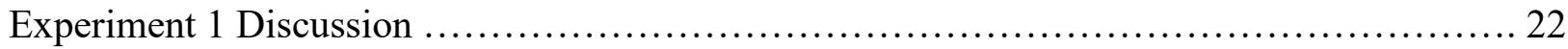

Experiment 2 Method............................................................ 25

Experiment 2 Results....................................................... 27

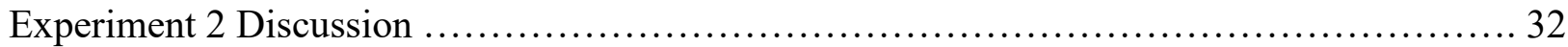

Experiment 3 Method.......................................................... 34

Experiment 3 Results............................................................. 36

Experiment 3 Discussion ...................................................... 38

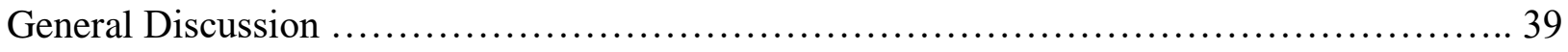

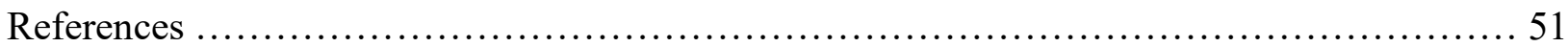


Organisms continually choose between different opportunities for reinforcement, be it food, friends, or workplace success. Many of these reinforcers depend on work requirements, and organisms will predominantly work on the easier of two requirements when multiple options are available. Although an organism normally only engages in one activity at a time, reinforcers can become available on other simultaneously available schedules of reinforcement as behavior is allocated to one activity. How choice between easier and harder response requirements is impacted by environmental variables currently is not well understood. These experiments examined some of the variables involved in determining these choices.

\section{Literature Review}

This review will first examine the general procedures employed in the experimental analysis of choice. Some of the schedules of reinforcement and data analysis techniques used in this research area will be described. Following this, choice between ratio and interval schedules will be compared, and an alternate procedure for assessing choice between ratio schedules will be introduced. This procedure was used throughout these experiments to explore how choice develops when reinforcers depend on response requirements rather than time requirements.

\section{Measuring choice}

In this document, choice is defined as the allocation of time or behavior to one activity among two or more alternatives (Baum \& Rachlin, 1969). Researchers studying choice frequently use concurrent schedules of reinforcement because they allow for the continuous measurement of choice. A concurrent schedule is established when responses are reinforced according to two or more simultaneously available schedules of reinforcement. A common form is a concurrent variable-interval (VI) VI schedule (Herrnstein, 1961). On a VI schedule, a reinforcer is made available following a variable amount of time. Once the interval has elapsed, 
one response is required for the reinforcer to be delivered. Concurrent VI VI schedules are advantageous for studying choice because the probability of reinforcement on both available schedules increases through time. As behavior is allocated to one option, the inter-reinforcement interval on the opposing schedule continues to elapse. Because of this arrangement, there is always a possibility that a reinforcer is available on either schedule. For these reasons, exclusive responding does not form and allocation of behavior is sensitive to relative changes in the schedules of reinforcement.

There are two primary methods of establishing a concurrent schedule. The first is a twokey arrangement (Ferster \& Skinner, 1957). Two response options are presented simultaneously, and distinct schedules of reinforcement are established on each alternative. When pigeons are subjects, responses to two separate keys are reinforced according to the schedule associated with each key. The second is a changeover-key procedure (Findley, 1958). Responses to one key, designated the main key, are reinforced according to one of the concurrently available schedules. A response to a second key, designated the changeover key, results in a stimulus change on the main key (usually key color) and changes the active schedule of reinforcement. Both procedures result in similar allocation of behavior and generally are considered to be functionally identical (Davison \& McCarthy, 1988), but the changeover-key procedure requires an explicit changeover response. When changeover responding is of interest, this latter method may be preferred for the straightforward analysis of changeovers. This method also allows a more precise measure of time allocation to each of the alternatives. Throughout this paper, the example used is of a changeover-key concurrent schedule in which the main key is red or green, with different-valued VI schedules correlated with each key color, and the changeover key is white. 
On a concurrent VI VI schedule, choice is defined by the ratio of responses or time allocated to the red and green keys. The results of roughly 50 years of research have demonstrated that the ratio of responses is a power function of the ratio of reinforcement available from both keys (Baum, 1974, 1979; Staddon, 1968, see Grace \& Hucks, 2013 for a review). This function has been identified using a multitude of both experimental conditions and naturalistic observations (Davison \& McCarthy, 1988; Poling, Edwards, Weeden \& Foster, 2011; Wearden \& Burgess, 1982). The power function relating response allocation to availability of reinforcement is known as the generalized matching law: the relative allocation of responses among two alternatives will match the relative frequency of reinforcement available from those alternatives (Baum, 1974, 1979). The generalized matching law can be written as

$$
\log \frac{B_{R}}{B_{G}}=a \log \frac{R_{R}}{R_{G}}+\log b
$$

where $B_{R}$ is response frequency on the red key, $B_{G}$ is response frequency on the green key, and $R_{R}$ and $R_{G}$ are frequency of reinforcement on the red and green key, respectively. The parameter $a$ represents sensitivity and describes the extent to which relative response allocation changes as relative availability of reinforcement changes. Higher sensitivity values reflect greater control by the contingencies. The parameter $b$ represents bias and describes what Baum (1974) considered to be variations in responding unrelated to the relative frequency of reinforcement. The matching law is commonly log-transformed because the log-transformed function becomes a linear relation, and this relation is easier to interpret visually than its untransformed, nonlinear counterpart. With this transformation, sensitivity is the slope of the linear function. A slope of 1.0 describes strict matching, or a 1 unit change in relative responding for every 1 unit change in relative reinforcement. Slopes greater than 1 indicate that more responses were allocated to the 
red or green key when more reinforcement was available from those keys. Slopes less than 1 indicate that responses were allocated more evenly between the two alternatives with respect to relative frequency of reinforcement. When concurrent VI VI schedules are implemented, regardless of other procedural variations, sensitivity values are normally less than 1 (e.g., organisms allocate behavior more equally than would be predicted by the matching law). The intercept of the function is the logarithm of the bias term. Intercepts greater or less than zero indicate that a relatively higher number of responses were allocated to the red or green key, respectively, regardless of the frequency of reinforcement available from the schedules. The slope and intercept are determined independently of each other, so sensitivity can be compared across subjects even when biases differ substantially.

In experimental analyses of choice using concurrent schedules, a changeover delay (COD, Herrnstein, 1961) typically is employed (but see Catania, 1963, for matching functions in the absence of a COD and Stubbs, Pliskoff, \& Reid 1977 for a changeover response requirement) to discourage rapid alternations between the two schedules. A COD specifies some interval of time following a changeover from one schedule to the other wherein no reinforcement is available. In other words, the COD penalizes switching between schedules. On two-key concurrent arrangements, the COD typically starts following the first peck to one of the two response options. In changeover-key concurrent schedules, the COD usually begins following a response to the changeover-key. Shull and Pliskoff (1967) manipulated the length of the COD when rats responded on changeover-lever concurrent VI VI schedules. As the COD increased from $0 \mathrm{~s}$ to $20 \mathrm{~s}$, the rate of changeovers declined rapidly. Silberberg and Fantino (1970) replicated these results using pigeons. In both experiments, the relative ratio of responses increasingly favored the schedule with a higher rate of reinforcement as the COD increased. 
When concurrent VI VI schedules are employed, estimates of sensitivity increase as the duration of the COD is lengthened. Fantino, Squires, Delbrück, and Peterson (1972), for example, studied COD durations of $.15 \mathrm{~s}, 1.5 \mathrm{~s}$, and $15 \mathrm{~s}$ with pigeons responding on concurrent VI VI schedules. Longer CODs resulted in larger relative response ratios favoring the schedule with a higher rate of reinforcement, and larger response ratios reflect an increased sensitivity of responding to the schedules of reinforcement.

Changeover requirements are important for choice research both procedurally and conceptually. Procedurally, sensitivity to reinforcement is usually lower when there is no changeover requirement. As described in the previous paragraph, CODs reduce changeover responses and, in turn, increase allocation of behavior toward one or the other alternative. In other words, without a COD response allocation will not be as affected by manipulations of independent variables. Additionally, changeover responses are operants separate from the responses allocated to the two concurrently available schedules (Catania, 1966). Dimensions of the changeover response, such as rate, can be modified by varied changeover requirements. Because behavior allocation and changeover responses vary as a function of the changeover requirement, CODs must be carefully considered. Conceptually, Baum (1982) argued that the COD can resemble travel requirements that occur in non-experimental choice settings. To forage in different patches of food, for example, an organism must travel from one to the other. This period of travel between concurrently available schedules of reinforcement necessarily takes some amount of time. Changeover requirements in experimental settings may be functionally analogous to natural delays between concurrent operants. To summarize, one constraint on concurrent operants, and thus choice, is the absence or presence of a COD and, in the latter case, 
its duration. It therefore is not possible to understand choice without understanding the COD context in which the concurrent operant responses are reinforced.

Any reinforcement schedule can be made concurrently available with any other schedule, and sometimes schedules other than VI schedules have been used in choice research. Such combinations of schedules to comprise the concurrent schedule have included, but are not limited to, concurrent fixed-interval (FI) VI (Nevin, 1971), FI FI (White \& Davison, 1973) FI fixed-ratio (FR) (Labounty \& Reynolds, 1973), FR FR (Herrnstein, 1958), FR variable-ratio (VR) (Rider, 1979) and VR VR schedules (Herrnstein \& Loveland, 1975). Although a detailed review of these schedules is beyond the scope of this review, response allocation on each of these concurrent schedules was differentially affected by changes in the schedule values. That being said, deviations from matching were observed frequently. Additionally, idiosyncratic patterns of responding tend to occur on arrangements other than concurrent VI VI schedules. On a concurrent FI VI schedule, for example, initially more responses are allocated toward the VI schedule. When the timer for the FI schedule has nearly elapsed, more responses are allocated to the FI schedule (Lattal \& Abreu-Rodrigues, 1997; Nevin, 1971). This pattern can be contrasted with performance on concurrent VI VI schedules, where responses are allocated more evenly through time. Because concurrent VI VI schedules provide the advantages described earlier, most of what we know about choice has been gleaned from this particular arrangement. The matching law constitutes a precise, mathematical understanding of choice behavior, but it does so most accurately only when concurrent VI VI schedules are implemented. Although concurrent VI VI schedules yield orderly data, is it fair to state that VI schedules should be used to characterize the entire world of choice? As has been shown above, choice can be made between 
a panoply of schedules. If the generalized matching law is to comprehensively describe choice, this function must be extended to a more diverse set of procedural arrangements.

\section{Choice and concurrent ratio schedules}

As an alternative to interval schedules, reinforcers can be made contingent on work requirements, rather than time requirements, on ratio schedules. On a ratio schedule, a specified number of responses are required for reinforcement to be delivered. The response requirement is

constant on a FR schedule. On a VR schedule the required number of responses varies following every reinforcer delivery, but the requirements average around some value. If the matching law is a general descriptive account of choice behavior, then it ought to be able to predict behavior allocated toward concurrently available ratio schedules. The extent to which response allocation and changeover responding on concurrent ratio schedules compare to concurrent interval schedules is described below.

Shull and Pliskoff (1971) measured the rate of changeovers maintained by concurrent VR-60 VR-60 and concurrent FR-60 FR-60 schedules using a changeover-key concurrent schedule. In one condition the schedules were programmed independently of each other. That is, responses toward one ratio requirement counted only toward the requirement for that schedule and did not affect the alternative schedule. When pigeons responded on either VR or FR schedules, changeovers occurred infrequently. Although there were few changeovers, there was no systematic preference between the concurrently available schedules. Herrnstein and Loveland (1975) extended these findings by establishing two-key concurrent VR VR schedules with response requirements ranging from 11 to 100. The concurrent schedules always were programmed independently of each other. Across phases, the response requirement on each concurrently available schedule varied and was sometimes equal (e.g., concurrent VR 30 VR 30) 
or unequal (e.g., concurrent VR 10 VR 50). When the ratio schedules were equal, responses were not systematically allocated to one schedule over the other. When the schedules were unequal, the pigeons pecked almost exclusively on the schedule with the lower response requirement. The relative allocation of responses was not well-described by the matching law because responding heavily favored the lower ratio requirement even when the relative difference between the two schedules was small.

Unlike concurrent VI VI schedules, the probability of reinforcement on independentlyarranged concurrent ratio schedules does not increase through time for both schedules as responses are allocated to a single schedule. As a pigeon responds on a red key, for example, the response counter is not incremented for the schedule associated with the green key. For this reason, Herrnstein and Loveland (1975) found that response allocation was not predicted by the generalized matching law. Even though reinforcement could be obtained on both schedules, the time between reinforcers was shortest when responses were allocated only to one schedule and changeovers occurred infrequently. Although the maximization of reinforcement was consistent with the matching of responses to reinforcement, the generalized matching law did not fit their data. This finding brings into question the generality of the matching law as a model for predicting choice if it cannot account for response allocation on concurrent ratio schedules. This shortcoming, however, may be a result of procedural limitations rather than of an unavoidable characteristic of ratio schedules.

In addition to the results described previously, Shull and Pliskoff (1971) compared the rate of changeovers on independent ratio schedules to changeovers on nonindependent concurrent VR VR and FR FR schedules. On nonindependent schedules, responses to the main key of one color (e.g., red) count equally for the schedule associated with the other color (e.g., 
green). Once the response requirement for a schedule is met, the reinforcer is withheld until one response occurs to the main key color associated with that schedule. By arranging the schedule in this way, the probability of reinforcer availability on both concurrently-available schedules increases in a manner similar to a concurrent VI VI schedule. Just as the inter-reinforcer interval of both VI schedules continues to pass as time is allocated toward one alternative, the response requirement of both ratio schedules can be met as responses are allocated toward either alternative on nonindependent concurrent ratio schedules. Pecks to the key of one ratio schedule increases the probability of reinforcement for responding on the other ratio schedule. In this arrangement, the rate of changeovers on a nonindependent VR-60 VR-60 schedule increased substantially compared to the independently programmed schedules. The response patterns were comparable to those observed on concurrent VI VI schedules. On a nonindependent concurrent FR-60 FR-60 schedule, however, the rate of changeovers was higher than on the independent arrangement for only one of the three pigeons exposed to this procedure. For the other two pigeons, the rate of changeovers was equivalent between the two kinds of schedules. Under the nonindependent condition, a high changeover rate was induced by concurrent VR VR schedules. If nonexclusive preference can be engendered by VR schedules, then it is possible that the generalized matching law could be used to predict response allocation on nonindependent ratio schedules.

In a further investigation of response allocation on concurrent ratio schedules, MacDonall (1988) maintained lever-pressing of four rats on independent and nonindependent changeoverlever concurrent VR VR schedules. The values of the VR schedules were varied across phases and were sometimes equal (e.g., VR 100 VR 100) or unequal (e.g., VR 250 VR 27.8). No COD was arranged. All rats responded on nonindependently arranged schedules, while two of the rats 
received additional training on independently arranged schedules at some point in the experiment. Under independent schedules, the rats responded almost exclusively to the smaller of the two ratio schedules and changed over between schedules infrequently. Nonindependent schedules engendered nonexclusive preference and a higher rate of changeovers, thus replicating Shull and Pliskoff's (1971) findings. Additionally, MacDonall used multiple pairs of VR schedules which allowed a fit of the generalized matching law (see Equation 1) to the relative response allocation of each rat. The generalized matching law described the data well by accounting for at least $97 \%$ of the variance in the data. Sensitivity values ranged from .58 to .91 for response allocation, where 1.0 is strict matching. Although some of the sensitivity values were substantially lower than 1 , any sensitivity value greater than 0 still shows some discriminative control by the schedules of reinforcement.

Meisch and Spiga (1998) likewise maintained responding on nonindependent VR VR schedules by three Rhesus monkeys. The monkeys responded by making lip contact with one of two available spouts, each of which was correlated with a distinct VR schedule. With the two VR schedules constant and equal throughout the study, varying concentrations of pentobarbital available from each response option were used as reinforcers. Relative reinforcer magnitude was manipulated by keeping the concentration of pentobarbital constant on one option while changing the concentration on the other option across phases. Exclusive preference did not develop using this procedure. Rather, the monkeys responded to both options proportionately to the concentration of pentobarbital available from each alternative. When applied to response allocation of each monkey, the generalized matching law accounted for $98 \%$ to $100 \%$ of the variance. Additionally, sensitivity values ranged from 1.11 to 1.77 across monkeys, which was substantially higher than MacDonall (1988) found with rats responding for food. It is unclear 
whether the difference in sensitivity between the two experiments was a result of the different species or reinforcer. In any case, Meisch and Spiga extended the applicability of the generalized matching law to choice on concurrent ratio schedules. In summary, MacDonall and Meisch and Spiga found that matching is not exclusive to concurrent interval schedules and can be induced by concurrent VR VR schedules. In this schedule arrangement, the probability of reinforcement increases on both schedules as responses are allocated to either response alternative. This characteristic overcomes the procedural limitations of independent ratio schedules that other researchers have found to engender exclusive preference (e.g., Herrnstein \& Loveland, 1975).

\section{Statement of the Problem}

Throughout their lives, organisms choose between many sources of reinforcement by distributing behavior across those sources. Because there are many available sources of reinforcement, an organism's behavior always is directed at some source of reinforcement at the expense of another. The way in which an animal's behavior is distributed between sources of reinforcement is called choice. These choices are ubiquitous, even when there is a single source of programmed reinforcement (Herrnstein, 1970), and to understand the behavior of organisms is to understand the variables that govern choice. Although choice has been extensively studied, there remain many dimensions of the process that are not understood.

Concurrent VI VI schedules of reinforcement predominately have been used to study choice in behavioral research. Variable-interval schedules yield measures of response allocation that are highly sensitive to the distribution of reinforcers without producing exclusive preferences or idiosyncratic patterns of responding on either alternative (Herrnstein, 1961). Because each VI schedule operates independently of the other, the inter-reinforcer interval of one schedule continues to elapse even as responses are allocated to the other schedule. In this way, 
the probability of a reinforcer being delivered from each key increases through time (see Davison \& McCarthy, 1988 for a review).

Although concurrent VI VI schedules have been instrumental in studying choice, the availability of reinforcers can be response-driven rather than time-driven. Concurrent ratio schedules allow for the study of choice when reinforcers are contingent on a number of responses rather than the passage of time. When concurrent ratio schedules are programmed independently, such that responses to one schedule do not affect the response requirement of the other schedule, responding characteristically is exclusive to the schedule with the fewest number of responses required (Herrnstein \& Loveland, 1975). Unlike the typical arrangement of VI schedules, the probability of reinforcement does not increase for both schedules when responses are allocated to either independent ratio schedule. Because of the independent arrangement, reinforcement is maximized by responding exclusively to the richer schedule without changing over to the leaner schedule.

An alternative method for assessing choice on concurrent ratio schedules is to arrange the schedules nonindependently (Shull \& Pliskoff, 1971). On a nonindependent concurrent ratio schedule, responses to either alternative increment the response counter for both ratio schedules. When the response requirement is met for one of the schedules, the reinforcer is delivered following the next eligible response on that schedule. This procedure is similar to a concurrent VI VI schedule in that the probability of reinforcement becoming available on both schedules increases as responses are allocated to either schedule. Because the procedure allows for simultaneous progress toward the completion of both ratio schedules, exclusive preference for one alternative over the other is not observed. Shull and Pliskoff found that the rate of changeovers on a nonindependent concurrent VR VR schedule was substantially higher for all 
subjects than the rate on independent concurrent VR VR or FR FR schedules. MacDonall (1988) also found that rats changed over more often on nonindependent VR VR schedules than on independently arranged schedules. Additionally, MacDonall showed that the relative allocation of responses upon the two alternatives was well-described by the generalized matching law (see Equation 1).

There is strong evidence that nonindependent ratio schedules produce changeovers, but effects of CODs have not been systematically analyzed. Changeover responses are operants that are integral to performance on concurrent schedules, and they are functionally related to variations in CODs. When concurrent VI VI schedules are employed, longer CODs increase relative response rates on the richer alternative and decrease the rate of changeovers between alternatives (Shull \& Pliskoff, 1967). In Experiment 1 the length of the COD was manipulated to investigate how sensitivity of response allocation and rate of changeovers varies as a function of COD.

Although Shull and Pliskoff (1971) compared concurrent VR VR and FR FR schedules, the primary dependent variable analyzed was changeover rate. Additionally, only one pair of schedules was used, so the generalized matching law could not be fit to their data. In Experiment 2, performance on concurrent VR VR and FR FR schedules were compared by alternating schedule types across days. The average response requirements for the two schedule types were equal within conditions but manipulated across conditions. Within-subject comparisons of sensitivity and changeover rate on concurrent VR VR and FR FR schedules allowed for an assessment of performance on these two types of schedules.

Under the nonindependent concurrent schedules described above, the distribution of reinforcers between the two available schedules is not directly controlled. The value of the ratio 
schedules was manipulated, but the pigeons could still earn all reinforcers from one alternative if responses were exclusively allocated to that option. In Experiment 3, the number of reinforcers delivered to each schedule was controlled (Stubbs \& Pliskoff, 1969). Across conditions, either the number of reinforcers delivered from each schedule or the value of the ratio schedule in effect was manipulated. This experiment extended the findings of Experiments 1 and 2 by investigating whether behavior varied as a function of the distribution of reinforcers or the value of the ratio schedules.

\section{Experiment 1}

\section{Method}

Subjects. Three experimentally naïve White Carneau pigeons (Columba livia) served as subjects. Each was maintained at $80 \%$ ad libitum weights through appropriate post-session feeding and housed individually in cages with a 12-hr:12-hr light:dark cycle with free access to water.

Apparatus. A three-key operant-conditioning chamber, $30 \mathrm{~cm}$ x $35 \mathrm{~cm}$ x $38 \mathrm{~cm}$ in dimension, enclosed in a sound-attenuating box was used. The chamber contained a ventilation fan that provided air circulation and white noise. Three keys were located on a single panel in the chamber, and a force of approximately .15 $\mathrm{N}$ was necessary to operate each key. The keys were $27 \mathrm{~cm}$ from the floor and spaced $1.5 \mathrm{~cm}$ apart. A houselight, located at the bottom right of the panel, provided general illumination at all times except during the pre-session blackout and during food delivery. A food hopper containing Nutriblend pigeon pellets was made available, when activated, through an aperture at the bottom of the panel below the keys. The aperture was $8.5 \mathrm{~cm}$ from the floor and $14 \mathrm{~cm}$ below the keys. The hopper was illuminated upon activation. A computer and MED-PC® interface located in an adjacent room controlled the sessions. 


\section{Procedure.}

Pre-training. After pigeons were taught to eat from the hopper, pecks to the left and right keys were hand-shaped. Training sessions then were conducted in which each peck to the left and right keys were reinforced. During training sessions the color of the left key was white, the right key alternated between red and green, and only one key was active at a time. Over a period of approximately one month the schedule was increased to a concurrent VR 30 VR 30 schedule (described below). During pre-training and all subsequent experimental conditions sessions terminated after 60 reinforcers were delivered. All sessions were conducted at approximately the same time on every day of the week.

Nonindependent Concurrent Schedule. Each session began with a 180 -s blackout during which the houselight and all key lights were dark. Following the blackout, a houselight turned on and the left and right keys were transilluminated. A concurrent VR VR schedule using a changeover-key procedure (Findley, 1958) was in effect on the side keys. The right key, designated the main key, was either red or green, depending on the active VR schedule. The left key, designated the changeover (CO) key, was always white. Responses to the main key were reinforced according to separate VR schedules correlated with the red and green colors. Following a response to the $\mathrm{CO}$ key, it was darkened and became inactive. Simultaneously, the key color and ratio schedule in effect on the main key changed. Following the first response to the main key, the changeover key turned on and became active again.

A nonindependent concurrent schedule was programmed such that responses on the main key incremented the response counters for both ratio schedules. When a reinforcer was available on one of the schedules, the response counter for that schedule did not advance until the 
reinforcer was collected. A reinforcer was delivered following the first eligible response to the main key color correlated with that schedule. As an example, on a concurrent VR 30 VR 30 schedule, 30 responses may be required by the schedule on the red key. The pigeon initially may peck 28 times on the red key before changing over to the green key. Following two pecks to the green key, the response requirement on the red key would be fulfilled. The pigeon would then need to change over to the red key and respond at least once before the reinforcer would be delivered.

Variable-ratio Schedules. Across the experiment, pigeons were exposed to several pairs of VR schedules with each pair of ratios summing to 60 . The values of all VR schedules were exponentially distributed (Fleshler \& Hoffman, 1962) with 20 values in each distribution. Values from each set of 20 were randomly selected without replacement until all 20 values had been used. Table 1 shows the order of presentation of VR schedules in each condition. The programmed pairs of VR schedules were: VR 30 VR 30, VR 25 VR 35, VR 15 VR 45, and VR 10 VR 50. These pairs of VR schedules constituted reinforcer ratios (shown red VR:green VR) of 1:1, 1:1.4, 1:3, and 1:5. These ratios show the relative number of responses required for reinforcement by each schedule. Within each condition (described below), three or four of the pairs were used across phases of a condition. The VR 30 VR 30 pair was presented first in each condition for all pigeons with subsequent pairs being presented in counterbalanced order across subjects. The key color associated with the smaller ratio also was counterbalanced across pairs. Each pair of ratios remained in effect for at least 15 sessions and until there were no systematic trends in response or time distributions determined by visual inspection.

Changeover Delay. Across conditions, varying lengths of CODs constituted the independent variable. Each response to the CO key initiated a timer. No responses were eligible 
for reinforcement until the timer elapsed. The first response to the main key that followed the lapse of the COD and met the response requirement of the schedule was reinforced. Table 1 also shows the order in which CODs were investigated for each pigeon. Changeover delays of $0 \mathrm{~s}, 2.5$ $\mathrm{s}$, and $10 \mathrm{~s}$ were used across conditions. After at least one response to the main key, a subsequent response to the changeover key produced a schedule change and initiated a new COD interval, even if the previous COD had not yet elapsed. Any responses during the COD continued to increment response counters for both schedules, but reinforcers were not available until the delay elapsed. A 0-s COD was in effect in the first condition for all pigeons. The 2.5-s and 10-s CODs were presented thereafter in counterbalanced order across pigeons.

\section{Results}

To quantify the extent to which behavior changed as a function of the contingencies of reinforcement, log-transformed ratios of reinforcers, responses, and time were calculated for the last 10 sessions of each condition. Reinforcer ratios are the number of reinforcers delivered from the schedule associated with the red key divided by the number of reinforcers delivered by the schedule associated with the green key. Response and time ratios are calculated in the same way, but instead use the number of responses and amount of time spent in each schedule, respectively. These ratios were then log-transformed. Because dividing by zero is impossible, a log ratio could not be calculated for sessions in which all reinforcers, responses, or time were allocated to a single alternative. For Pigeon 11829, 24 response and time ratios in the 10-s COD condition could not be calculated. For Pigeon 11993, 6 ratios in the 0-s COD condition, 5 ratios in the 2.5-s COD condition, and 11 ratios in the 10-s COD could not be calculated. For Pigeon 13719, 12 ratios in the 2.5-s COD condition and 13 ratios in the 10-s COD could not be calculated. 
To show the extent to which behavior conformed to the generalized matching law (see Equation 1), simple linear regressions with reinforcer ratios as predictor variables and response or time ratios as dependent variables were conducted for each pigeon. The slope of the resulting equation is the sensitivity of responding to the contingencies of reinforcement; the y-intercept shows any bias for one key over another. Figure 1 shows log response ratios as a function of log reinforcer ratios for each pigeon across all CODs. Each data point is a response ratio calculated from a single session. The solid lines and accompanying equations show fits of Equation 1. Sensitivity values ranged from .64 to 1.36 across all conditions and pigeons, showing that choice changed in accordance with the distribution of reinforcers. Sensitivity values were greater than 1 for all pigeons when a $0-\mathrm{s}$ COD was in effect, and sensitivity generally decreased as CODs increased. No reliable biases were observed for any pigeons. Finally, $\mathrm{R}^{2}$ values ranged from .82 to .94 for all linear regressions, showing that Equation 1 accounted for a substantial portion of the variance in response ratios.

Because response ratios could not be calculated for many of the sessions, as described above, the number of responses and reinforcers allocated to each schedule were summed across the last 10 sessions of each phase. Response and reinforcer ratios were calculated from these sums, and simple linear regressions were conducted for each pigeon in each condition using the aggregated ratios. Figure 2 shows these $\log$ response ratios as a function of log reinforcer ratios for each pigeon across all CODs. Sensitivity values ranged from .52 to 1.37 across all conditions and pigeons, corroborating the analysis described above with single session data. Similar patterns were shown as compared to the above analysis, wherein sensitivity was highest with a 0-s COD and decreased as the COD was lengthened. $\mathrm{R}^{2}$ values were all .93 or greater, which was greater than the single session data. Because there were only 3 or 4 data points in each condition, 
however, relatively high $\mathrm{R}^{2}$ values should be expected. Because of the similarities in singlesession and aggregated response ratios, only the sensitivity values calculated using single-session response ratios will be considered below.

Figure 3 shows log time ratios as a function of log reinforcer ratios for each pigeon across all CODs. As in Figures 1 and 2, solid lines and accompanying equations show fits of Equation 1. Sensitivity values ranged from .48 to .90 showing that time ratios, while generally less sensitive than response ratios, changed as a function of reinforcer ratios. For pigeons 11829 and 11993, sensitivity values were greatest when a 0-s COD was in effect, decreased or remained about the same with a 2.5-s COD, and was lowest with a 10-s COD. For pigeon 13719, sensitivity was the lowest with a 0 -s COD and greatest with a 10-s COD. As with response ratios, no reliable biases were observed for any pigeons. With one exception, $\mathrm{R}^{2}$ ranged from .74 to .95 across pigeons and conditions, showing that time ratios were well described by Equation 1 . An $\mathrm{R}^{2}$ of .34 was calculated in the 10 -s COD condition for pigeon 11829 , but the large number of incalculable ratios ( 24 sessions with exclusive preference for one alternative) likely limited the applicability of Equation 1 to account for this data.

For ease of comparison, Figure 4 shows estimates of sensitivity for response and time ratios calculated by the linear regressions described above for all pigeons across all conditions. Sensitivity of response ratios were similar across the three pigeons. Sensitivity was highest with a 0-s COD, lower with a 2.5-s COD, and, with one exception, lowest with a 10-s COD. For 11829, sensitivity was slightly higher with a 10-s COD than a 2.5-s COD. Sensitivity of response ratios was almost always higher than the sensitivity for time ratios with the same COD. Pigeons responded relatively more to the smaller of two ratio schedules compared to the amount of time they allocated to that same alternative. All three pigeons had distinct patterns of sensitivity for 
time ratios across the three CODs. For 11829, sensitivity decreased as the COD increased. For 11993, sensitivity remained about the same across all three CODs. Sensitivity increased for 13719 as the COD was increased. Although there were ordinal difference in patterns of sensitivity across the three pigeons, there was not as large of a range for time ratios (range: .49 $.90)$ as for response ratios (range: .64-1.36).

Differences in the rate of changeovers can impact the extent to which responding is sensitive to the schedules available on the concurrently available options. Figure 5 shows mean rate of changeovers from the last 10 sessions of each phase as a function of reinforcer ratio in effect for each pigeon across all conditions. Two general patterns in changeover rate emerged: 1) rate of changeovers tended to decrease as reinforcer ratios were more disparate and 2) rate of changeovers decreased as the COD was increased. Except for 13719 with a 0 -s COD and 11993 with a 2.5-s COD, pigeons changed over less often when the difference between the two ratio schedules was greater. Across conditions, the rate of changeovers was usually highest when the ratio schedules were equal (1:1 ratio) and always lowest when the schedules were most different (1:3 or 1:5 ratios). Changeover rates did not decrease substantially, and occasionally increased, from 1:1 to $1.4: 1$ ratios, demonstrating that these VR schedules were not functionally different enough to produce large changes in response patterns. Changeover rates during 1:3 and 1:5 ratios, however, were consistently lower than rates during 1:1 and 1.4:1 ratios. These lower rates are consistent with the larger response and time ratios shown in Figures 1 and 3. In other words, pigeons allocated behavior less equally when reinforcer ratios were more unequal, consistent with predictions of the generalized matching law.

Increases in the COD also reduced changeover rates for all pigeons. The increase in COD from 0 to $2.5 \mathrm{~s}$ decreased changeover rates for 11993 and 13719, and the 10-s COD extinguished 
changeovers almost entirely for all pigeons regardless of reinforcer ratio. This reduction in changeovers with a 10-s COD accounts for the many incalculable reinforcer, response, and time ratios during this condition. In many cases, pigeons would respond exclusively to the red or green schedule that began the session (selected randomly by the computer) or changeover once to the smaller of the two available schedules. Finally, 13719 changed over more frequently than either 11829 or 11993 (note the change in axis in Figure 5). Although these changeovers did not have much effect on the number of responses allocated to the two schedules, increased changeovers likely influenced the allocation of time to each alternative. This may explain why changes in sensitivity for time ratios (see Figure 3) were distinct for this pigeon.

Sensitivity and changeover rates are useful for examining overall effects of concurrent schedules, but they do not clearly examine behavior as it is being distributed during a session. Run lengths and visit durations show the amount of responses or time, respectively, allocated to an alternative per visit to that schedule. Run lengths are calculated by dividing the number of responses on a schedule by the number of changeovers to that schedule. Visit durations are the amount of time spent on a schedule divided by the changeovers to the schedule. Table 2 shows mean run lengths and visit durations from the last five sessions of each phase for red and green schedules for all pigeons through all conditions. Although these data vary considerably, there are clear patterns evident through the experiment. When the concurrent VR schedules were similar (1:1 and 1.4:1 ratios), a similar amount of responses and time were allocated to each key for every visit. For example, 11829 in the 1:1 ratio with a 0 -s COD responded 16.50 and 10.24 times per visit to the red and green key, respectively. He spent 11.20 and $8.85 \mathrm{~s}$ in the presence of the red and green keys, respectively, in the same condition. As reinforcer ratios became more disparate (i.e. 1:3 and 1:5 ratios), the pigeons responded many more times on the smaller of the 
two VR schedules relative to the larger schedule. During the 1:3 ratio with a 0 -s COD, 11829 responded on the red key 477 times for every 10.54 responses on the green key. Similarly, he spent 220.62 and 6.13 s per visit to the red and green keys, respectively. When few changeovers were made, as in all conditions with a 10-s COD, run lengths and visit durations vary considerably because a large number of responses or amount of time was divided by a small number of changeovers (sometimes only 1 or 2). Regardless, these data demonstrate that pigeons distribute behavior roughly equally when concurrent VR schedules are similar. When the VR schedules are more different they switch to a fix-and-sample pattern wherein they predominately respond to the smaller of the two VR schedules before briefly sampling the larger VR schedule.

\section{Discussion}

The generalized matching law describes behavior allocation on concurrent schedules by generating a sensitivity value, and this value describes the extent to which behavior allocation changes as relative reinforcement rates vary on the component schedules. In doing so, sensitivity quantifies shifts in preference where low values describe indifference and greater values describe more exclusive preference. When concurrent VI VI schedules are used, sensitivity values are typically less than 1 (Baum, 1974), but sensitivity of response ratios was greater than 1 for all pigeons in the current experiment when a 0-s COD was in effect. Additionally, including a COD increases sensitivity to concurrent VI VI schedules (e.g., Fantino, Squires, Delbrück, \& Peterson, 1972), but as CODs were increased across conditions in the present experiment, sensitivity of

response ratios declined. Although the rate of changeovers decreased with longer CODs, pigeons also allocated behavior more evenly between the concurrently available VR schedules. MacDonall (1988) found the response allocation of rats was sensitive to reinforcer ratios when VR schedules were nonindependently programmed, with sensitivity estimates consistently less 
than 1. When monkeys responded for pentobarbital on nonindependent concurrent VR schedules, behavior allocation consistently resulted in sensitivity values greater than 1 (Meisch and Spiga, 1998). MacDonall suggested that nonindependent concurrent VR VR schedules are functionally similar to concurrent VI VI schedules, but the findings from the present Experiment 1 and from Meisch and Spiga (1998) suggest that there are functional differences in performance between concurrent VI VI and concurrent VR VR schedules. Reinforcers are limited by the interreinforcer intervals programmed by the experimenter on VI schedules, whereas reinforcers are limited only by response rates on VR schedules. This distinction resulted in systematically different performance as a function of the COD duration on nonindependent concurrent VR VR schedules compared to concurrent VI VI schedules. Regardless, the generalized matching law described response allocation well in the present experiment, suggesting that concurrent VR VR schedules are a viable procedure for studying choice.

Sensitivity to reinforcer ratios was greater for response ratios than time ratios in this experiment, but both dependent variables conformed to the predictions of the matching law. MacDonall (1988) similarly found that response ratios were substantially more sensitive to reinforcer ratios than time ratios for 3 of 4 rats. These findings diverge from choice on concurrent VI VI schedules wherein time ratios are reliably more sensitive than response ratios (Baum, 1974). On concurrent VR VR schedules, responses occur multiple times per second and reinforcers are delivered as a function of the number of responses occurring. The amount of time spent on each alternative is irrelevant to the delivery of reinforcers, except that more time is spent on a schedule when more responses are allocated to that schedule. Insofar as sensitivity describes the discriminability of the concurrently available schedules, differential performance on each alternative demonstrates discriminability between the schedules. If response ratios are 
reliably more sensitive to reinforcer ratios, then response allocation, as opposed to time allocation, may be a better measure of preference when responding on concurrent VR VR schedules is of interest.

Although response and time ratios did not vary systematically, the absolute values of these ratios occasionally had a high range. This was particularly true when the component VR schedules were most different, and this is likely due to the lack of experimenter control over the distribution of reinforcers throughout a session. Because reinforcers depended on meeting the response requirements of the schedule, rather than time requirements, the number of reinforcers delivered from each schedule sometimes varied considerably across sessions. The variability in reinforcer deliveries in turn affected the allocation of behavior. Even when conditions were continued for many sessions, the dynamic feedback between reinforcer ratios and behavior allocation resulted in variable response and time ratios. Behavior allocation may have stabilized further if each condition was continued for even more sessions, but the unsystematic trends in response and time ratios across sessions was deemed appropriate for changing conditions. Despite the lack of control over reinforcer ratios and the resulting variability in behavior allocation, response and time ratios still were well-described by the matching law.

Experiment 1 showed that the generalized matching law described performance on nonindependent concurrent VR VR schedules, but the generality of the findings does not extend to fixed-ratio schedules. Shull and Pliskoff (1971), for example, found that pigeons did not changeover at as high of a rate on nonindependent concurrent FR FR schedules compared to a similar arrangement with concurrent VR VR schedules. Their results pointed to an important distinction between fixed- and variable-schedule performance in concurrent arrangements, but there is a paucity of research comparing sensitivity of response allocation on these schedules. 
Notably, Shull and Pliskoff did not vary the values of the component ratio schedules to assess such effects on response and time allocation. In Experiment 2 performance on nonindependent concurrent VR VR and FR FR schedules was investigated to determine the relative efficacy of the generalized matching law in describing behavior under both schedules.

\section{Experiment 2}

\section{Method}

Subjects. Five White Carneau pigeons (Columba Livia) served as subjects. Each had previous experience responding under various schedules of food reinforcement. Each was maintained at $80 \%$ ad libitum weights through appropriate post-session feeding. The pigeons were housed individually in cages with a 12-hr:12-hr light:dark cycle with free access to water.

Apparatus. A six-key operant-conditioning chamber, $30 \mathrm{~cm}$ x $30 \mathrm{~cm}$ x $25 \mathrm{~cm}$ in dimension, enclosed in a sound-attenuating box was used. The chamber contained a ventilation fan that provided air circulation and white noise. The six keys were located on a single panel; one row of four keys were arranged above a second row of two keys. The row of two keys were $19 \mathrm{~cm}$ from the floor and spaced $8 \mathrm{~cm}$ apart. The row of four keys were $27 \mathrm{~cm}$ from the floor and spaced $4 \mathrm{~cm}$ apart. In this experiment, only the rightmost three keys on the top row were used. These three keys will hereby be referenced as the left, middle, and right keys. The three other keys remained dark and inactive throughout the study. A force of approximately $0.15 \mathrm{~N}$ was necessary to operate each key. A houselight, located on the ceiling on the opposite side of the chamber as the panel, provided general illumination at all times except during the pre-session blackout and during food delivery. A food hopper containing Nutriblend pigeon pellets was made available for $3 \mathrm{~s}$, when activated, through an aperture at the bottom of the panel below the keys. The aperture was $7.5 \mathrm{~cm}$ from the floor and $7 \mathrm{~cm}$ below the bottom row of keys. The 
hopper was illuminated upon activation. A computer and MED-PC® interface located in an adjacent room controlled the sessions.

\section{Procedure.}

Pretraining. Pigeons were trained as in Experiment 1, except that they did not need initial training to eat from the hopper. Additional training sessions were conducted wherein the right key alternated between blue and orange and responses to the key were reinforced.

Conditions. The general procedure was the same as described for Experiment 1. All concurrent schedules used a changeover-key procedure (Findley, 1958) and sessions terminated after 60 reinforcer deliveries. Daily sessions alternated pseudo-randomly between concurrent VR VR and concurrent FR FR schedules (described below). Each schedule was associated with distinct locations and colors of the main key. The session type was selected randomly each day.

The programmed ratio schedules constituted the independent variable. Three pairs of ratios were used across the experiment, and all pairs of ratios summed to 120 . The pairs of ratios were $60 / 60,50 / 70$, and 100/20. Although the absolute values of the ratio schedules differed from Experiment 1, these pairs similarly constituted reinforcer ratios of 1:1, 1:1.4, and 1:5. Across conditions, the pair of ratios in effect was manipulated. The order in which pairs of ratios were presented and the key color associated with the smaller ratio was counterbalanced across pigeons and conditions. Table 3 shows the order of conditions for each pigeon. Although the pair of ratios changed across conditions, the ratio schedules in effect were the same for the concurrent VR VR and concurrent FR FR schedules within conditions. Each session type required the same number of responses on average, but the specific response requirements differed between the concurrent VR VR and concurrent FR FR schedules. Regardless of condition and schedule type, a 2.5-s COD operated as described in Experiment 1. Each condition remained in effect, with one 
exception, until at least 15 sessions of both schedule types had been conducted (a minimum of 30 session in total) and until no systematic trends in response or time ratios were observed.

Concurrent Variable-Ratio Schedule. The concurrent VR VR schedule was programmed nonindependently, as in Experiment 1. Every response to the main key incremented the response counter for both ratios in the concurrent schedule. During Concurrent VR VR sessions, the left key was designated the main key and it was either red or green, depending on the active schedule. Responses to the main key were reinforced according to separate VR schedules associated with each key color. The center key, colored white, was used for the changeover key. Following a response to the changeover key, the color and schedule on the main key changed and the changeover key was darkened and became inactive. After one response to the main key, the center key became active again. The right key remained dark and inactive for the entirety of these sessions.

Concurrent Fixed-Ratio Schedule. The concurrent FR FR schedule was programmed similarly to the concurrent VR VR schedule, except that FR schedules were in effect instead. Responses to the main key still incremented the response counter for both ratio schedules. During concurrent FR FR sessions, the right key was designated the main key and it was either blue or orange. Responses to the main key were reinforced according to separate FR schedules associated with each key color. The center key was also the changeover key, and it was white. The changeover key functioned identically as in the VR VR schedule. The left key remained dark and inactive for the entirety of these sessions.

\section{Results}

Log-transformed ratios of reinforcers, responses, and time were calculated for the last 10 VR and FR sessions for each condition. As in Experiment 1, there were some sessions in which 
pigeons exclusively responded to one or the other alternative. Incalculable ratios were generated 5 times for Pigeon 2748, 3 times for Pigeon 3181, 7 times for Pigeon 795, and 9 times for Pigeon 9553. All incalculable ratios occurred during conditions with 1:5 or 5:1 reinforcer ratios, and all but two ratios for Pigeon 9553 occurred during VR sessions. Data from these sessions were not included in any analyses concerning response or time ratios.

To show the extent to which responding conformed to the generalized matching law (see Equation 1), simple linear regressions with reinforcer ratios as predictor variables and response or time ratios as dependent variables were conducted separately for VR and FR sessions for each pigeon. Figure 6 shows log response ratios as a function of $\log$ reinforcer ratios for VR and FR sessions for all pigeons. Each data point is a response ratio calculated from a single session, and solid lines and accompanying equations show fits of Equation 1. In VR sessions, sensitivity values ranged from .49 to 1.08 , demonstrating that response ratios were sensitive to concurrent VR schedules. Aside from Pigeon 9553, sensitivity values were greater than .85, and sensitivity may have been lower for 9553 due to seven incalculable response ratios in the 1:5 reinforcer ratio condition. Across all pigeons, $\mathrm{R}^{2}$ values ranged from .90 to .98 , showing that Equation 1 described response ratios well when concurrent VR VR schedules were in effect.

Across FR sessions, two apparent patterns in response ratios were observed. Pigeons either responded similarly as during VR sessions or responded about equally to the concurrent schedules regardless of the reinforcer ratio. Pigeons 2748 and 9553 had sensitivity values greater than .7 with accompanying $\mathrm{R}^{2}$ values of .98 and .82 , respectively. Response ratios for these pigeons clearly changed as a function of reinforcer ratios as predicted by the generalized matching law. Pigeons 3181, 4079, and 795 had sensitivity values of .36, .16, and .58, respectively. Additionally, $\mathrm{R}^{2}$ values, ranging from .14 to .78 , were lower for these pigeons 
compared to pigeons 2748 and 9553. Although reinforcer ratios changed across conditions, response ratios were not affected as greatly.

Because response ratios could not be calculated from some sessions, aggregated response and reinforcer ratios were calculated by summing the number of responses and reinforcers allocated to each alternative from the last 10 sessions of each condition for all pigeons. Figure 7 shows these aggregated response ratios as a function of reinforcer ratios for each pigeon separately for VR and FR sessions. Sensitivity values were generally similar to those calculated using single-session response ratios. The largest difference in sensitivity across all pigeons was for Pigeon 9553 in FR sessions, with a sensitivity of .76 and .66 for single session and aggregated response ratios, respectively. For this reason, only the single-session response ratios will be referred to below.

The relative amount of time spent at each alternative was generally similar to the relative number of responses allocated. Figure 8 shows log time ratios as a function of log reinforcer ratios with accompanying fits of Equation 1. As with response ratios, sensitivity was high in VR sessions for all pigeons, ranging from .53 to 1.02. Aside from Pigeon 9553, sensitivity was equal to or greater than .85 for all pigeons. Across all pigeons, $\mathrm{R}^{2}$ values ranged from .87 to .98 , demonstrating that Equation 1 described time ratios well. For pigeons 2748 and 9553, sensitivity in FR sessions was .73 and .63 with $\mathrm{R}^{2}$ values of .98 and .90 , respectively. For these two pigeons, the generalized matching law described time ratios similarly under concurrent VR VR and FR FR schedules. Although sensitivity was lower for pigeons 3181, 4079, and 795, with estimates of $.42, .40$, and .56 , respectively, $\mathrm{R}^{2}$ values of .80 for Pigeon $3181, .73$ for Pigeon 4079, and .91 for Pigeon 795 showed that time ratios were similarly well-described by Equation 1. The relatively low sensitivity for time ratios combined with the poor fits for response ratios, 
however, suggests the generalized matching law makes inconsistent predictions about responding in concurrent FR FR schedules.

The two distinct patterns of sensitivity in concurrent FR FR schedules was accompanied by different rates of changeovers across pigeons. Figure 9 shows mean changeovers per min from the last 10 sessions of each condition as a function of reinforcer ratio for FR and VR sessions for all pigeons. When concurrent VR VR schedules were in effect, all pigeons changed over at a relatively high rate when the two ratio schedules were similar (i.e., 1:1 and 1.4:1 ratios) and at a much lower rate when the schedules were disparate (i.e., 1:5 ratio). During FR sessions, pigeons 2748 and 9553 had similarly high changeover rates when the FR schedules were similar. With a 1:5 or 5:1 ratio in effect, changeover rates decreased substantially for both pigeons. For pigeons 3181, 4079, and 795 changeover rates showed a different pattern in FR sessions compared to VR sessions. When 1:1 and 1:1.4 ratios were in effect, changeover rates in FR sessions were similar to or lower than rates during VR sessions. During conditions with 1:5 or 5:1 ratios, changeover rates were substantially higher during FR sessions than VR sessions. In contrast to VR sessions, changeover rates during FR sessions were similar across all conditions for pigeons 4079 and 795 and were only clearly different for Pigeon 3181 when comparing conditions with 1:1 and 5:1 ratios.

When changeover rates are high during conditions with disparate ratio schedules, as observed in pigeons 3181,4079 , and 795 , then behavior is probably being distributed more equally between the two alternatives. This equal distribution of behavior would produce lower sensitivity, which is consistent with the previously described analyses. High changeover rates, however, do not directly show how much behavior is allocated per changeover. Tables 4 and 5 show mean run lengths and visit durations, respectively, to each key from the last 5 sessions of 
each condition for VR and FR sessions for all pigeons. In cases where pigeons never changed over to a schedule, run lengths and visit durations could not be calculated. During VR sessions, run lengths and visit durations varied as a function of reinforcer ratio. In conditions with 1:1 reinforcer ratios, a similar number of responses and amount of time were allocated to each key per changeover. As an example, Pigeon 2748 responded an average of 32.19 and 32.93 times and spent 7.22 and $7.34 \mathrm{~s}$ to the red and green keys, respectively, per changeover. With a 1:1.4 reinforcer ratio, all but Pigeon 9553 allocated more behavior per changeover to the smaller ratio schedule. Pigeon 2748, for example, responded 44.64 times to the smaller ratio for every 16.93 responses to the larger ratio and similarly spent 8.37 and $4.74 \mathrm{~s}$ to the respective schedules. Finally, run lengths and visit durations were most different in conditions with 1:5 or 5:1 reinforcer ratios. Pigeon 2748 responded 1224.50 times and spent 189.90 s per visit to the smaller ratio schedule; run lengths and visit durations could not be calculated for the larger schedule because no changeovers to that schedule occurred in any of the last five sessions for this pigeon. A similar pattern was observed for all pigeons during VR sessions.

Run lengths and visit durations were similar in FR sessions compared to VR sessions for pigeons 2748 and 9553, but differed for pigeons 3181, 4079, and 795. Pigeons 2748 and 9553 responded in FR sessions in a similar manner as the patterns described above for VR sessions. Behavior was equally allocated per changeover when ratio schedules were similar but unequally allocated when ratio schedules were more different. Pigeons 3181, 4079, and 795 all allocated behavior similarly to the two keys regardless of reinforcer ratio. For example, per changeover Pigeon 3181 responded to the orange and blue keys 21.59 and 25.74 times in the 1:1 condition, 31.73 and 28.78 times in the 1.4:1 condition, and 41.54 and 68.64 times in the 5:1 condition. Visit durations were also similar across conditions. Although more behavior was allocated per 
changeover to the smaller ratio during the 5:1 condition, the difference is not as large as in VR sessions. These data combined with the previous analyses show that pigeons 3181,4079 , and 795 changed over frequently during FR sessions and allocated similar amounts of behavior per changeover to each key regardless of reinforcer ratio. These patterns in changeover behavior produced more equal allocation of responding and thus lower estimates of sensitivity.

\section{Discussion}

In Experiment 2 performance on nonindependent concurrent VR VR and FR FR schedules was compared. The concurrent VR VR sensitivity results replicated the concurrent VR VR performance in Experiment 1 and those of MacDonall (1988) and Meisch and Spiga (1998). In contrast to the findings for the VR components, two patterns of responding occurred during FR sessions. For two pigeons, sensitivity during FR sessions was relatively high and comparable to sensitivity during VR sessions. For the other three pigeons, sensitivity of response and time ratios was substantially lower during FR compared to VR sessions. The latter suggests that, for these three pigeons, the two available schedules were not discriminably different from one another even when the ratio values were most disparate. These pigeons changed over between the two FR schedules at a similar rate across the different conditions and collected reinforcers from both schedules. This changeover pattern resulted in smaller reinforcer ratios, that is, a more equal distribution of reinforcers between the two schedules. Because reinforcers were distributed evenly between the response options, the concurrently available FR schedules were functionally similar and did not result in differential performance.

When comparing nonindependent concurrent VR-60 VR-60 and FR-60 FR-60 schedules, Shull and Pliskoff (1971) also found inconsistent changeover patterns on concurrent FR FR schedules. Two of three pigeons changed over infrequently, but the third changed over at a 
relatively high rate. Although the proportion of reinforcement received from both response options was similar for all pigeons, the three pigeons responded disproportionately more to one or the other schedule. These response patterns were dissimilar to those in the present experiment, wherein all five pigeons changed over frequently and responded about equally to both response options when the two FR requirements were identical. Because Shull and Pliskoff only used one pair of ratio schedules, estimates of sensitivity could not be calculated, and this precluded comparing response allocation across varied reinforcer ratios.

The uncontrolled distribution of reinforcers inherent in nonindependent concurrent ratio schedules likely resulted in the inconsistent patterns of behavior observed on concurrent FR FR schedules. On a nonindependent concurrent VR VR schedule, in both Experiments 1 and 2, changing over frequently from a smaller-valued ratio schedule to a relatively larger-valued ratio schedule is not optimal because reinforcement is not consistently available from the relatively lean schedule. Responding primarily on the smaller ratio schedule and occasionally sampling the larger schedule results in many reinforcers earned from the former schedule without wasted time responding on the latter schedule. This "fix-and-sample" pattern is similar to that observed on concurrent VI VI schedules (Baum, Schwendiman, \& Bell, 1999). This response pattern was observed for all pigeons when concurrent VR VR schedules were most disparate. Two of the pigeons responded similarly when concurrent FR FR schedules were imposed. For example, Pigeon 2748 responded an average of 275.24 times per visit to the FR 20 schedule compared to 25.45 times to the FR 100 schedule during the 5:1 reinforcer ratio condition. After responding 100 times to the FR 20 schedule, a reinforcer would have been available from the FR 100 schedule. Many more responses were allocated to the FR 20 schedule and changeovers occurred infrequently, so reinforcers were available that were not collected from the FR 100 schedule. 
Because the distribution of reinforcers was not controlled, this pattern of responding resulted in reinforcers being distributed similarly to a concurrent VR VR schedule. For the three pigeons that changed over more frequently during FR sessions, reinforcers were reliably collected from both alternatives even when the schedules were most disparate.

The two patterns of responding under the concurrent FR FR schedule described above resulted in differing distributions of reinforcers. When responses were allocated evenly, reinforcers were then distributed more equally even when the component FR schedules were different. With an equal distribution of reinforcers, responses upon both schedules continued to be reinforced. Given the underlying rationale of the matching law - that behavior tracks reinforcement - the even response ratios under concurrent FR FR schedules is conceptually commensurate with the predictions of the matching law. The variable response patterns across pigeons and experiments (e.g., Shull \& Pliskoff, 1971), however, reflects a lack of experimental control over reinforcer ratios. Due to the intertwined relation between responses, changeovers, and reinforcers on ratio schedules, it is difficult to predict exactly how reinforcers will affect subsequent choice on these schedules. If the distribution of reinforcers could be experimentally controlled, then it is plausible that the variables determining behavior allocation would be elucidated. In Experiment 3, nonindependent concurrent VR VR schedules were programmed such that the number of reinforcers delivered to each response option was controlled, and sensitivity of response allocation was assessed under these conditions.

\section{Experiment 3}

\section{Method}

Subjects. Same as in Experiment 1. 
Apparatus. Same as in Experiment 1.

\section{Procedure.}

Nonindependent Concurrent Schedule. The general procedure was similar to

Experiment 1. Each session began with a 180-s blackout. Following the blackout, a houselight turned on and the left and right keys were transilluminated. A concurrent VR VR schedule using a changeover-key procedure (Findley, 1958) was in effect on the side keys. As in Experiment 1, the right key was the main key and, depending on the VR schedule, was either red or green. The left key was the changeover key and it was white. A 2.5-s COD, as described in Experiment 1, was in effect throughout the experiment.

A nonindependent concurrent schedule was programmed such that responses on the main key incremented the response counters for both ratio schedules. Unlike in Experiment 1, a reinforcer was available only from one schedule at a time (Stubbs \& Pliskoff, 1969). At the start of the session and following every reinforcer delivery, the computer selected one of the available schedules to be active. Responses to the active schedule were reinforced if they fulfilled the ratio and COD requirement, and responses to the other schedule incremented response counters but could not be reinforced. Following reinforcement, the computer again selected one of the two schedules to be active. In other words, reinforcers were available from both schedules throughout a session, but changeovers were required to collect all reinforcers.

Ratio Requirement Manipulation. Table 6 shows the order of conditions for all pigeons. For two of the pigeons, 11993 and 13719, the ratio requirements of the VR schedules were manipulated across conditions. In all sessions, the computer selected the red and green schedules after each reinforcer such that 30 reinforcers were received in red and green during each session. Across conditions, the pair of VR requirements were VR 30 VR 30, VR 25 VR 35, and VR 10 
VR 50. Thesed constitute reinforcer ratios of 1:1, 1:1.4, and 1:5, respectively. Both pigeons experienced the VR 30 VR 30 pair first, with other pairs presented in counterbalanced order across conditions.

Active Schedule Manipulation. For Pigeon 11829, the number of reinforcers available from each schedule was manipulated across conditions. In all sessions, a concurrent VR 30 VR 30 schedule was in effect. Across conditions, the number of times each schedule was active (i.e., reinforcers delivered from each schedule) in a session (shown red/green) were 30/30, 39/21, 9/51, and 51/9. These constituted reinforcer ratios of 1:1, 1:1.8, 5.6:1, and 1:5.6, respectively.

\section{Results}

Log-transformed ratios of reinforcers, responses, and time were calculated for the last 10 sessions of each condition. Reinforcer ratios for Pigeon 11829 were calculated by dividing the number of reinforcers delivered from the red schedule by the number of reinforcers delivered from the green schedule. Reinforcer ratios for Pigeons 11993 and 13719 were calculated by dividing the VR value on the red key by the VR value on the green key. Simple linear regressions (see Equation 1) with reinforcer ratios as predictor variables and response or time ratios as dependent variables were conducted. Figure 10 shows log response ratios (top row) and $\log$ time ratios (bottom row) as a function of $\log$ reinforcer ratio for all pigeons. Each data point is a response ratio calculated from a single session, and solid lines and accompanying equations show fits of Equation 1. The number of reinforcers delivered to each alternative was manipulated for Pigeon 11829 (left column of Figure 10) and the VR schedules in effect for each alternative were manipulated for Pigeons 11993 and 13719 (right two columns of Figure 10).

Behavior allocation varied as a function of reinforcer ratio when the number of reinforcers delivered form each schedule was manipulated. Sensitivity values for Pigeon 11829's 
response and time ratios were $.92\left(\mathrm{R}^{2}=.97\right)$ and $.67\left(\mathrm{R}^{2}=.98\right)$, respectively. When an equal number of reinforcers were delivered from each schedule, a similar amount of behavior was allocated to each alternative regardless of what ratio schedules were in effect. Sensitivity values for response ratios were $.13\left(\mathrm{R}^{2}=.36\right)$ for Pigeon 11993 and $.07\left(\mathrm{R}^{2}=.35\right)$ for Pigeon 13719 . Sensitivity values for time ratios were $.03\left(\mathrm{R}^{2}=.11\right)$ and $.04\left(\mathrm{R}^{2}=.07\right)$ for Pigeons 11993 and 13719 , respectively. Behavior was allocated according to Equation 1 only when the number of reinforcers available from each schedule was manipulated and not when the ratio schedules on each key differed.

The rate at which pigeons changed over was also different when comparing the two procedures for delivering reinforcers. Figure 11 shows mean changeover rates from the last 10 sessions of each condition for all pigeons. Pigeon 11829 changed over at a similar rate under reinforcer ratios of 1:1 and 1:1.8, but changeovers were reduced when the reinforcer ratio was either 1:5.6 or 5.6:1. The reduced rate of changeovers when the relative allocation of reinforcers was more different suggests that Pigeon 11829 allocated relatively more behavior to the schedule delivering more reinforcers, as shown by the sensitivity values of response and time ratios described previously. Pigeon 11993 changed over slightly more often under 1:5 and 5:1 ratios compared to the 1:1 ratio, and Pigeon 13719 changed over at about the same rate regardless of reinforcer ratios. The change in VR schedules across conditions did not substantially affect changeover rate for either of these pigeons, consistent with their sensitivity of response and time ratios.

The two procedures for delivering reinforcers also produced differences in the amount of behavior allocated per visit to an alternative. Table 7 shows mean run lengths and visit durations for all pigeons from the last five sessions of each condition for both the red and green keys. 
Pigeon 11829 allocated a similar amount of behavior, both responses and time, per visit to each key when a 1:1 reinforcer ratio was in effect. As the reinforcer ratios became more different, relatively more behavior was allocated per changeover to the schedule that delivered more reinforcers. This effect was relatively mild with the 1:1.8 reinforcer ratio and more substantial with the 1:5.6 and 5.6:1 ratios. Pigeons 11993 and 13719, however, responded similarly to each alternative regardless of the reinforcer ratio in effect. With one small exception, about the same number of responses and amount of time was allocated per changeover across all conditions. In the 1:5 ratio condition, Pigeon 11993 responded an average of 16.78 and 29.40 times to the red and green keys, respectively. While this was the largest difference in any condition for either of these pigeons, there were no consistent changes in run lengths or visit durations as a function of reinforcer ratio. Only when the two concurrently-available ratio schedules delivered differing amounts of reinforcement did behavior consistently change as a function of reinforcer ratio.

\section{Discussion}

Either the number of reinforcers delivered or the concurrent ratio schedules in effect were manipulated in this experiment while the other variable was held constant. When the ratio schedule values were changed across conditions, the pigeons changed over at similar rates and allocated similar amounts of behavior to either alternative, independently of the reinforcer ratio. When the number of reinforcers delivered from the two schedules varied, the pigeon changed over less often when reinforcers were distributed unequally across the schedules and behavior allocation varied as a function of the reinforcer ratio. Together with results of Experiments 1 and 2, these findings suggest that behavior during concurrent VR VR schedules is allocated according to the distribution of reinforcers rather than according to the value of the ratio schedules in effect. 
The finding that response allocation varied as a function of reinforcer distribution highlights the differences in response allocation among the pigeons under the concurrent FR FR schedules in Experiment 2. When reinforcers were distributed equally or unequally on the two FR schedules, the pigeons allocated behavior accordingly. The results of Experiment 3 show that the distribution of reinforcers can be controlled and, by doing so, response allocation can be controlled more precisely. By experimentally controlling the distribution of reinforcers on nonindependent concurrent FR FR schedules, response allocation may become more sensitive to reinforcer ratios as in concurrent VR VR schedules.

Without controlling the reinforcement delivery on concurrent ratio schedules, reinforcers are unpredictably delivered according to the behavior of the organism. Insofar as the number of reinforcer deliveries on a schedule covaries with the value of the ratio schedule in effect, behavior allocation still would vary with changes in the reinforcer ratio. This appears to be true for concurrent VR VR schedules, as shown by the results of Experiments 1 and 2, but was inconsistently demonstrated on the concurrent FR FR schedules studied in Experiment 2. By manipulating only the ratio schedule response requirements, however, choice is controlled indirectly. The results of Experiment 3 show that choice can be directly controlled in ratio schedules by manipulating reinforcer distribution rather than the value of the ratio schedules. This finding is similar to performance controlled by concurrent VI VI schedules, where reinforcer ratios also are controlled (Stubbs \& Pliskoff, 1969). In both cases, behavior allocation can be precisely predicted by the programmed reinforcer ratios.

\section{General Discussion}

Across all three experiments, choice, measured by either response or time allocation, varied on concurrent VR VR schedules as a function of reinforcer ratios as predicted by Equation 
1. In combination with previous findings (MacDonall, 1988; Meish \& Spiga, 1998; Shull \& Pliskoff, 1967), these results demonstrate that nonindependent concurrent VR VR schedules can yield performance comparable to that obtained with the more usually investigated concurrent VI VI schedules. Taken together, these experiments extend the generality of the generalized matching law to contexts in which choices are made between simultaneously available ratio schedules. In contrast, when VR schedules are arranged concurrently but independently (e.g., Herrnstein \& Loveland, 1975), responding occurs exclusively to the schedule associated with the smaller VR and changeovers between schedules are infrequent. When concurrently available ratio schedules are programmed independently of one another, the probability of reinforcement on one alternative is unaffected by responses to the alternate option. Reinforcers are only accrued on the schedule in which responses are allocated, and thus more reinforcers are earned by responding exclusively to one option. Under nonindependent concurrent ratio schedules, however, the probability of reinforcement increases on both schedules when responses are allocated to either option. In these conditions, reinforcers can be distributed on both schedules even when responses are allocated differentially.

\section{Reinforcer Distribution}

The way that reinforcer deliveries are programmed determines the allocation of behavior between alternative sources of ratio-based reinforcement. The critical variable determining behavioral differences between independent and nonindependent concurrent ratio schedules is the way in which reinforcers are distributed on the two schedules. Indeed, reinforcer distribution affects response allocation even depending on how nonindependent ratio schedules are programmed. Choice differed in Experiment 2 when reinforcers were contingent on variable or fixed response requirements and in Experiment 3 when the number of reinforcers distributed to 
each response option was controlled. The common variable controlling choice throughout all three experiments was the distribution of reinforcers. This basic notion is not novel, as it is the underlying rationale of the generalized matching law (Herrnstein, 1961), and these findings extend a long history of choice research by demonstrating similar functional relations between behavior allocation and reinforcement that occurs on concurrent interval schedules with ratiobased schedules of reinforcement.

Unlike concurrent VI VI schedules, wherein the distribution of reinforcers is experimentally controlled by determining the inter-reinforcer intervals on each schedule, the precise distribution of reinforcers on nonindependently-programmed concurrent ratio schedules is determined not by the experimenter but by the organism's behavior. In Experiments 1 and 2, the distribution of reinforcers was controlled only indirectly - by manipulating the response requirement of the ratio schedules. Response rates and patterns generated by the programmed schedules were the actual determinants of reinforcement rate and pattern. Although behavior allocation was controlled by reinforcer ratios, response and time ratios were variable and there were many sessions in which these ratios could not be calculated due to exclusive preference for one or the other response option. To avoid these problems, reinforcer ratios allocated across two schedules can be directly controlled by assigning reinforcers to each schedule according to some algorithm, as was done by Stubbs and Pliskoff (1969) with concurrent VI VI schedules and in Experiment 3 with concurrent VR VR schedules. Under this arrangement, reinforcers are necessarily distributed between the two schedules (as determined by the experimenter), and all programmed reinforcers cannot be obtained by exclusively responding on one option. Even though reinforcement rate was still determined by response rate in Experiment 3, behavior allocation was controlled by the programmed distribution of reinforcers. Even when the value of 
the VR schedules was manipulated (as was the case for two pigeons in Experiment 3), response ratios were determined primarily by the distribution of reinforcers. Under both concurrent VI VI and nonindependent concurrent ratio schedules, behavior is allocated to the two alternative schedules as a function of the reinforcers earned on each schedule. In other words, behavior tracks reinforcement, as predicted by the generalized matching law, whether those reinforcers depend on time or response requirements, so long as the probability of reinforcement increases with the passage of time on each schedule.

\section{Differences between Concurrent VI VI and VR VR Schedules}

Although choice varied with the distribution of reinforcers on concurrent VR VR schedules in the present experiments, there were notable differences in sensitivity compared to choice on concurrent VI VI schedules. Sensitivity describes the extent to which the two concurrently available schedules are discriminable from one another. Differential reinforcement rates drive performance on the two schedules, and higher sensitivity values describe increasingly differential response allocation. The results of decades of choice research has shown that sensitivity values are typically less than 1 when concurrent VI VI schedules are investigated (what is labeled undermatching, Baum, 1974; Mazur, 1991). Responding is more equally distributed between the schedules than the reinforcement rates obtained from each alternative would predict based on strict matching (Herrnstein, 1961) when VI schedules are programmed. Additionally, longer CODs generally increase sensitivity under these conditions by punishing alternation between the schedules. In contrast to findings using concurrent VI VI schedules, sensitivity was greater than 1 for all pigeons in Experiment 1 when no COD was in effect. Sensitivity systematically decreased for all three pigeons as COD duration increased. Based on research in which CODs were not programmed between concurrently available VR schedules, 
MacDonall (1988) suggested that nonindependent concurrent VR VR schedules were functionally equivalent to concurrent VI VI schedules. The differences in sensitivity between the interval- and ratio-comprised concurrent schedules revealed by investigating choice as a function of COD duration suggests otherwise.

Behavioral differences between concurrent VI VI and VR VR schedules likely relate to differential constraints on reinforcement rate between the two schedules. On concurrent VI VI schedules, reinforcers are limited by the inter-reinforcer intervals programmed on each schedule. To maximize the number of reinforcers earned, responding needs to occur steadily, but not necessarily rapidly, on both of the available schedules. On nonindependent concurrent VR VR schedules, however, reinforcers are limited by the rate of responding under each schedule. Time spent not responding on the concurrent ratio schedules increases the delays to reinforcement, thereby decreasing the rate of reinforcement. Even the short period of time required to change over from one schedule to another can delay reinforcement; this is especially true when a COD is in effect. Without a COD, responding in Experiment 1 occurred almost exclusively to the schedule with the lower ratio requirement when 1:3 and 1:5 reinforcer ratios were in effect. This suggests that reinforcers could be earned so quickly that the short delay inherent in changing over led to noticeable delays to reinforcement. Although changeover-key concurrent schedules (Findley, 1958), as used in the current experiments, and two-key concurrent schedules (e.g., Herrnstein, 1961) yield similar results when both component schedules are VI (Davison \& McCarthy, 1988), the two-key method may reduce sensitivity on concurrent ratio schedules by decreasing the amount of time to complete the changeover requirement. Simply changing over once to respond on a second key would naturally take less time than changing over, responding on a changeover-key, and changing over again (as required by a changeover-key concurrent 
schedule). When reinforcers are based on response requirements, this slight delay may actually impact sensitivity to the reinforcer ratios.

With a COD in effect, sensitivity decreased in the present experiments (i.e., behavior was allocated more evenly) because the pigeons continued to respond on a schedule following a changeover even if the average response requirement on that schedule was higher. When ratio schedules are programmed nonindependently, the COD generates a period in which responses do not increment the response counter. Even a 2.5-s delay may noticeably lower reinforcement rates following changeovers. For this reason, continuing to respond on a relatively larger ratio schedule may be optimal because changing over could delay reinforcement even if responses were allocated to the smaller ratio schedule. Although CODs affect responding on concurrent VI VI schedules, the delay may punish changeovers to a greater extent when ratio schedules are programmed. A changeover response requirement (Pliskoff \& Fetterman, 1981), wherein a number of responses is required to change to the alternative schedule rather than a delay in which reinforcers are unavailable, at first blush may be more appropriate when organisms are responding on concurrent ratio schedules. Reinforcement would still be constrained by a changeover requirement, but the completion of the requirement would depend on the behavior of the organism much like the programming of the reinforcement schedules. Although completing the response requirement would necessarily take time, this time could be reduced by responding more quickly. A changeover response requirement still would penalize rapid alternations but might also reduce the amount of time spent in a period during which responses on the foodproducing operandum do not increment response counters. This alternate approach to reducing changeovers is potentially useful, but also might be functionally similar to a COD in that the required responses necessarily take time. One downside to a response requirement is that the 
time it takes to complete the requirement would vary, perhaps functioning as a variable COD, and would put less control in the hands of the investigator. Using a brief COD may be sufficient for preventing strict alternation without substantially impacting reinforcement rates. In any case, variations in changeover requirements and key arrangements (e.g., two-key schedule rather than changeover-key schedule) may produce substantial differences in choice compared to that observed in the present experiments.

\section{Behavior Allocation as Time or Responses}

Baum and Rachlin (1969) demonstrated that behavior allocation on concurrent VI VI schedules varied with reinforcement rate when pigeons allocated time, as opposed to discrete responses, upon two schedules of reinforcement. When pigeons received food for standing on one side or another of a chamber according to separate VI schedules, behavior was allocated in accordance with the generalized matching law. In typical concurrent VI VI arrangements, sensitivity of time ratios is usually greater than response ratios when concurrent VI VI schedules are in effect (Baum, 1979). For these reasons, Baum (2012) suggested time allocation to be the most useful measure of behavior allocation among concurrently available schedules of reinforcement. The day-to-day life of a person, for example, can be conceptualized in terms of the allocation of different amounts of time to various activities as a function of the reinforcement obtained from those activities. By foregoing binary responding and simply measuring time spent in an activity, Baum (1976) argued that descriptions of behavior can be improved by allowing all behavior to be measured on the common scale of time. This conceptualization may not be sufficient, however, when schedules of reinforcement with response requirements are in place.

In the present experiments, response ratios were consistently more sensitive to changes in reinforcer ratios than time ratios. Although time was still allocated to each alternative, in that 
pecking on a key takes time, responses were differentially allocated to the two component VR schedules more precisely than time. This finding highlights a potential limitation of time allocation as a primary dependent measure for studying choice. Although time may be allocated to an activity, such allocation may not directly coincide with the work contributed to the schedule of reinforcement, as seen in the present experiments. For example, a student writing an essay may spend hours staring at a blank word document on the computer, but until enough responses (or pecks) are made on the keyboard, the essay will not be written. This is similar to a pigeon spending time in the presence of a ratio schedule without any responses being made: time is being allocated, but reinforcers are not being earned. It may not be how much time you spend that is important, but instead how you spend that time. When reinforcers depend on response requirements, the relative number of responses made to concurrent alternatives may be a more appropriate measure of preference. When investigating choice among two or more concurrently available schedules, the present findings suggest that dependent variables are most usefully matched to the task at hand by considering which measures best describe the data.

\section{Implications of Choice in Concurrent Ratio Schedules}

Herrnstein's (1961) matching law has generated extensive research examining changes in choice with respect to relative changes in contingencies of reinforcement. This dynamic relation between behavior and reinforcement has influenced another area of research called behavioral economics. According to Hursh (1984), behavioral economics applies the rigorous empirical base of behavior-analytic experiments to principles of economics that are less grounded by experimentation. A basic principle of behavioral economics is that the value of some commodity (reinforcer) depends both on the price (schedule) of the commodity and the characteristics of simultaneously available commodities. Choice changes when the price of a concurrently 
available commodity changes, as shown by matching research, but behavioral economics experiments have also shown changes in choice as a function of different kinds of available reinforcers. For example, response rates on a schedule delivering food will increase as a function of the availability of water on a separate schedule (called a complementary relation). Typically, FR or progressive-ratio schedules are used in behavioral economics experiments because of the price of the schedule is precisely specified (price equal to the value of the FR). Concurrent FR FR schedules can be used to assess changes in responding on one schedule delivering food as a function of the price of water on the other schedule, and these concurrent schedules are usually programmed independently. If these concurrent schedules were programmed nonindependently, as in the present experiments, relative changes in choice would likely change with the dynamic changes in price that occur on nonindependent concurrent FR FR schedules. Nonindependent concurrent ratio schedules may be effective at answering behavioral economics questions, such as those about substitutable and complementary reinforcers, by assessing changes in behavior in relation to relative changes in the price of reinforcers.

In addition to the conceptual considerations of applying the matching law to choice amongst ratio schedules, studying choice when reinforcers depend on response requirements may have implications for how humans allocate behavior in nonlaboratory environments aside from those discussed in the previous paragraph. For example, researchers have applied the generalized matching law to behavior allocation in sports including basketball (Vollmer \& Bourret, 2000), baseball (Poling, Weeden, Redner, and Foster, 2011), and football (Reed, Critchfield, \& Martens, 2006). There are many concurrent choice arrangements in athletics, and the generalized matching law has been successful at describing the behavior of athletes. Despite the successes of this research, there are disconnects between choice in athletics and past choice research. Most 
schedules of reinforcement inherent in sports would best be described as ratio schedules (as they depend on a number of responses completed) rather than interval schedules. Basketball players must attempt many shots in order to score, even the best baseball players require multiple attempts to score a run, and golfers carefully measure the number of hits they make to the ball (although the schedule of reinforcement is inverted in this case). Examples of interval schedules are rare in athletics because there are not many cases where reinforcement can be earned for one response following some interval of time. Despite these examples, most choice research has shown the generalized matching law to be applicable only to concurrent VI VI schedules. In addition to this limitation, choice research in athletics is primarily archival and nonexperimental, which calls into question the applicability of the generalized matching law. The present experiments suggest a relation between choice on concurrent VI VI schedules and naturalistic contexts in which human behavior is allocated between concurrent ratio schedules. Behavior allocation varies as a function of reinforcer ratios on concurrent VR VR schedules so long as the probability of reinforcement increases on both schedules as responses are allocated. For a brief example of how this may apply in sports, basketball players are (for the most part) presented with two options for scoring: a 2-point and a 3-point basket. Each player makes some percentage of each type of shot that they attempt, and this can be interpreted as responding on two random-ratio or VR schedules. As a team or player makes more 3-point shots, however, the defense may begin making those shots more difficult (i.e., the value of the ratio schedule becomes relatively larger). This change in the ratio schedules may lead to more attempts at 2-point shots. Although this interplay in sports is not perfectly analogous to the nonindependent concurrent ratio schedules employed in this study, the present findings lend credence to the applicability of the generalized matching law to naturalistic contexts in which 
reinforcers are delivered according to ratio schedules. Translational research in this area could further our understanding of how humans and other organisms choose amongst a variety of concurrently available schedules of reinforcement.

\section{Conclusions}

The generalized matching law (Baum, 1974) is a primary method for assessing choice on concurrent schedules of reinforcement. Despite decades of empirical and theoretical support, however, the generalized matching law largely has been confined to describing performance on concurrent VI VI schedules. Reinforcers can be made contingent upon several dimensions of behavior (cf. Gilbert, 1958), however, including time and number of responses. If the matching law is to be considered a broad conceptualization of how behavior is allocated, then it ought to be able to describe and predict behavior when reinforcers depend on response requirements as well as time requirements. Shull and Pliskoff (1971), MacDonall (1988), and Meisch and Spiga (1998) demonstrated that response allocation varied as a function of reinforcement rates on concurrent ratio schedules when those schedules were programmed nonindependently. Compared to the substantial literature on the topic of choice among concurrently available VI schedules, very little is known about the variables governing behavior when ratio schedules are arranged. The present experiments extended previous findings by assessing changes in response allocation as a function of CODs, comparing performance on concurrent VR VR and FR FR schedules, and demonstrating precise control over reinforcer ratios on concurrent VR VR schedules.

Time is allocated to concurrently available activities in accordance with the reinforcement available from those activities (Baum, 2012), but behavior on nonindependent concurrent ratio schedules also varies as a function of the work required to obtain reinforcement. 
Previously, independent concurrent ratio schedules produced exclusive preference because reinforcers were not made available on both schedules over time, and this consideration has limited the applicability of the generalized matching law to describe response allocation. The present findings show this limitation to be merely procedural rather than conceptual. Rather than the matching law being a description of how organisms respond upon concurrent VI VI schedules, this line of research shows that similar functional relations between behavior allocation and reinforcement are observed when response requirements are imposed. That response allocation varies with respect to work requirements supports the notion that the generalized matching law is a broad perspective on how organisms allocate behavior amongst the many schedules of reinforcement available in the environment. 


\section{References}

Baum, W. M. (1974). On two types of deviation from the matching law: bias and undermatching. Journal of the Experimental Analysis of Behavior, 22, 231-242.

Baum, W. M. (1976). Time-based and count-based measurement of preference. Journal of the Experimental Analysis of Behavior, 26, 27-35.

Baum, W. M. (1979). Matching, undermatching, and overmatching in studies of choice. Journal of the Experimental Analysis of Behavior, 32, 269-281.

Baum, W. M. (1982). Choice, changeover, and travel. Journal of the Experimental Analysis of Behavior, 38, 35-49.

Baum, W. M., \& Rachlin, H. C. (1969). Choice as time allocation. Journal of the Experimental Analysis of Behavior, 12, 861-874.

Catania, C. (1963). Concurrent performances: A baseline for the study of reinforcement magnitude. Journal of the Experimental Analysis of Behavior, 6, 299-300.

Catania, C. (1966). Concurrent Operants. In W. K. Honig (Ed.), Operant behavior: Areas of research and application (213 - 270). New Jersey: Prentice-Hall Baum 1982

Davison, M., \& McCarthy, D. (1988). The matching law: A research review. University of Hillsdale, NJ: L. Erlbaum.

Fantino, E., Squires, N., Delbruck, N., \& Peterson, C. (1972). Choice behavior and the accessibility of the reinforcer. Journal of the Experimental Analysis of Behavior, 18, 3543.

Ferster, C. B., \& Skinner, B. F. (1957). Schedules of Reinforcement. New York: AppletonCentury-Crofts. 
Findley, J. D. (1958). Preference and switching under concurrent scheduling. Journal of the Experimental Analysis of Behavior, 1, 123-144.

Fleshler, M. \& Hoffman, H. S., (1962). A progression for generating variable-interval schedules. Journal of the Experimental Analysis of Behavior, 5, 529-530.

Gilbert, T. F. (1958). Fundamental dimensional properties of the operant. Psychological Review, 65, 272-282.

Grace, R. C., \& Hucks, A. D. (2013). The allocation of operant behavior. In Madden, G. J., Dube, W. V., Hackenberg, T. D., Hanley, G. P., \& Lattal, K. A. (Eds.), APA handbook of behavior analysis, Vol. 1: Methods and principles (307 -337). Washington, DC, US: American Psychological Association.

Herrnstein, R. J. (1958). Some factors influencing behavior in a two-response situation. Transactions fo the New York Academy of Sciences, 21, 35-45.

Herrnstein, R. J. (1961). Relative and absolute strength of response as a function of frequency of reinforcement. Journal of the Experimental Analysis of Behavior, 4, 267-272.

Herrnstein, R. J. (1970). On the law of effect. Journal of the Experimental Analysis of Behavior, $13,243-266$.

Herrnstein, R. J., \& Loveland, D. H. (1975). Maximizing and matching on concurrent ratio schedules. Journal of the Experimental Analysis of Behavior, 24, 107-116.

Hursh, S. R. (1984). Behavioral economics. Journal of the Experimental Analysis of Behavior, 42, 435-452.

Labounty, C. E., \& Reynolds, G. S. (1973). An analysis of response and time matching to reinforcement in concurren t ratio-interval schedules. Journal of the Experimental Analysis of Behavior, 19, 155-166. 
Lattal, K. A., \& Abreu-Rodrigues, J. (1997). Response-independent events in the behavior stream. Journal of the Experimental Analysis of Behavior, 68, 375-398.

MacDonall, J. S. (1988). Concurrent variable-ratio schedules: Implications for the generalized matching law. Journal of the Experimental Analysis of Behavior, 50, 55-64.

Meisch, R. A., \& Spiga, R. (1998). Matching under nonindependent variable-ratio schedules of drug reinforcement. Journal of the Experimental Analysis of Behavior, 70, 23-34.

Nevin, J. A. (1971). Rates and patterns of responding with concurrent fixed-interval and variable-interval reinforcement. Journal of the Experimental Analysis of Behavior, 16, 241-247.

Pliskoff, S. S., \& Fetterman, J. G. (1981). Undermatching and overmatching: The fixed-ratio changeover requirement. Journal of the Experimental Analysis of Behavior, 36, 21-27.

Poling, A., Edwards, T. L., Weeden, M., \& Foster, T. M. (2011). The matching law. The Psychological Record, 61, 313-322.

Poling, A., Weeden, M. A., Redner, R., \& Foster, T. M. (2011). Switch hitting in baseball: Apparent rule-following, not matching. Journal of the Experimental Analysis of Behavior, 96(2), 283-289.

Reed, D. D., Critchfield, T. S., \& Martens, B. K. (2006). The generalized matching law in elite sport competition: football play calling as operant choice. Journal of Applied Behavior Analysis, 39(3), 281-297.

Rider, D. P. (1979). Concurrent ratio schedules: Fixed versus variable response requirements. Journal of the Experimental Analysis of Behavior, 31, 225,237. 
Shull, R. L., \& Pliskoff, S. S. (1967). Changeover delay and concurrent schedules: Some effects on relative performance measures. Journal of the Experimental Analysis of Behavior, 10, 517-527.

Shull, R. L., \& Pliskoff, S. S. (1971). Changeover behavior under pairs of fixed-ratio and variable-ratio schedules of reinforcement. Journal of the Experimental Analysis of Behavior, 16, 75-79.

Silberberg, A., \& Fantino, E. (1970). Choice, rate of reinforcement, and the changeover delay. Journal of the Experimental Analysis of Behavior, 13, 187-197.

Staddon, J. E. R. (1968). Spaced responding and choice: a preliminary analysis. Journal of the Experimental Analysis of Behavior, 11, 669, 682.

Stubbs, D. A., Pliskoff, S. S., \& Reid, H. M. (1977). Concurrent schedules: A quantitative relation between changeover behavior and its consequences. Journal of the Experimental Analysis of Behavior, 27, 85-96.

Stubbs, D. A., \& Pliskoff, S. S. (1969). Concurrent responding with fixed relative rate of reinforcement. Journal of the Experimental Analysis of Behavior, 12, 887-895.

Vollmer, T. R., \& Bourret, J. (2000). An application of the matching law to evaluate the allocation of two-and three-point shots by college basketball players. Journal of Applied Behavior Analysis, 33(2), 137-150.

Wearden, J. H., \& Burgess, I. S. (1982). Matching since Baum (1979). Journal of the Experimental Analysis of Behavior, 38, 339-348.

White, A. J., \& Davison, M. C. (1973). Performance in concurrent fixed-interval schedules. Journal of the Experimental Analysis of Behavior, 19, 147-153. 
Table 1

Order of conditions for each subject in Experiment 1 VR

\begin{tabular}{ccccc} 
Subject & COD $(\mathrm{s})$ & (red/green) & Sessions & Order \\
\hline \hline 11829 & 0 & $30 / 30$ & 41 & 1
\end{tabular}

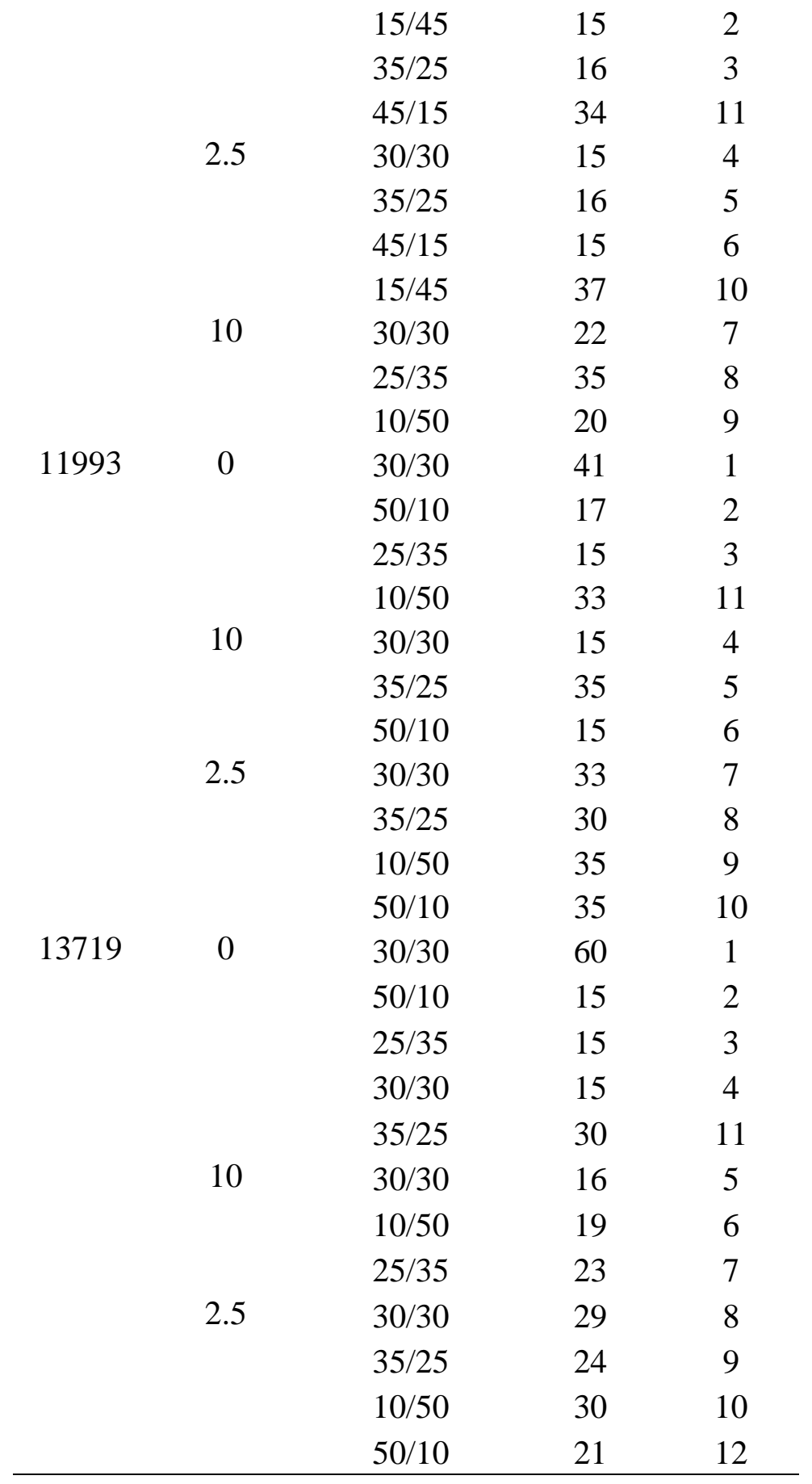

Note: $C O D=$ changeover Delay; $V R=$ variable-ratio. . 


\begin{tabular}{|c|c|c|c|c|c|c|}
\hline \multicolumn{6}{|l|}{ Table 2} & \\
\hline & \multicolumn{2}{|c|}{ Condition } & \multicolumn{2}{|c|}{ Mean Run Length } & \multicolumn{2}{|c|}{ Mean Visit Duration } \\
\hline Subject & $\mathrm{COD}(\mathrm{s})$ & Reinforcer Ratio & Red Key & Green Key & Red Key & Green Key \\
\hline \multirow[t]{11}{*}{11829} & 0 & $1: 1$ & $16.50(2.21)$ & $10.24(2.31)$ & $11.20(0.80)$ & $8.85(1.17)$ \\
\hline & & $1.4: 1$ & $14.05(1.67)$ & $18.11(2.85)$ & $10.42(1.73)$ & $13.81(1.58)$ \\
\hline & & $1: 3$ & $477(382.71)$ & $10.54(5.41)$ & $220.62(165.95)$ & $6.13(32.18)$ \\
\hline & & $3: 1$ & $2.42(0.31)$ & $59.68(14.43)$ & $4.58(0.33)$ & $32.18(8.40)$ \\
\hline & 2.5 & $1: 1$ & $15.74(2.45)$ & $14.55(1.46)$ & $9.38(1.12)$ & $8.56(.76)$ \\
\hline & & $1.4: 1$ & $11.80(2.42)$ & $29.38(7.75)$ & $7.78(1.67)$ & $14.40(3.51)$ \\
\hline & & $3: 1$ & $11.91(0.75)$ & $101.58(38.69)$ & $8.44(0.94)$ & $47.12(16.13)$ \\
\hline & & $1: 3$ & $835.90(209.30)$ & $1.27(1.92)$ & $420.86(103.11)$ & $8.41(5.61)$ \\
\hline & 10 & $1: 1$ & $2.20(4.92)$ & $1833.60(9.21)$ & $4.55(10.18)$ & $946.59(47.59$ \\
\hline & & $1: 1.4$ & $187.20(183.92)$ & $1902.20(276.94)$ & $150.36(145.45)$ & $483.92(398.87)$ \\
\hline & & $1: 5$ & $602.25(46.21)$ & $744.00(1312.38)$ & $365.98(78.55)$ & $306.63(426.44)$ \\
\hline \multirow[t]{11}{*}{11993} & 0 & $1: 1$ & $36.24(7.15)$ & $22.02(4.61)$ & $10.02(1.79)$ & $7.48(0.73)$ \\
\hline & & $1: 1.4$ & $97.27(13.71)$ & $18.59(9.09)$ & $21.51(2.63)$ & $6.66(1.98)$ \\
\hline & & $5: 1$ & 11.35 (14.69) & $187.21(105.71)$ & $5.94(4.20)$ & $58.73(40.24)$ \\
\hline & & $1: 5$ & $537.20(186.91)$ & $5.05(10.21)$ & $175.96(64.63)$ & $4.30(4.38)$ \\
\hline & 2.5 & $1: 1$ & $34.78(37.39)$ & $270.89(130.04$ & $10.51(9.37)$ & $58.83(27.11)$ \\
\hline & & $1.4: 1$ & $18.94(12.55)$ & $13.88(12.70)$ & $7.92(3.35)$ & $3.94(5.73)$ \\
\hline & & $1: 5$ & $463.05(223.91)$ & $12.70(12.30)$ & $108.82(91.59)$ & $5.73(5.45)$ \\
\hline & & $5: 1$ & $11.60(12.74)$ & $602.20(32.07)$ & $6.20(6.09)$ & $198.74(15.69)$ \\
\hline & 10 & $1: 1$ & $1507.60(490.50)$ & $422.80(516.46)$ & $323.15(100.17)$ & $81.3(97.78)$ \\
\hline & & $1: 1.4$ & $600.60(483.71)$ & $1056(352.36)$ & $117.24(93.00)$ & $214.88(78.09)$ \\
\hline & & $1: 5$ & $662.00(965.78)$ & $582.80(181.11)$ & $125.97(184.80)$ & $141.78(45.46)$ \\
\hline \multirow[t]{3}{*}{13719} & 0 & $1: 1$ & $11.98(1.53)$ & $12.93(1.62)$ & $6.76(1.01)$ & $6.72(0.93)$ \\
\hline & & $1: 1.4$ & $9.99(2.61)$ & $4.66(1.54)$ & $4.61(0.67)$ & $3.32(0.60)$ \\
\hline & & $5: 1$ & $3.75(1.43)$ & $107.15(57.59)$ & $13.64(11.38)$ & $37.87(16.61)$ \\
\hline
\end{tabular}




\begin{tabular}{ccccccc} 
& $1.4: 1$ & $229.96(207.62)$ & $411.99(366.49)$ & $147.66(131.49)$ & $193.16(170.66)$ \\
2.5 & $1: 1$ & $35.14(2.69)$ & $10.91(0.95)$ & $12.28(2.48)$ & $7.51(1.27)$ \\
& $1.4: 1$ & $18.21(3.43)$ & $38.22(5.15)$ & $6.69(0.57)$ & $14.35(7.31)$ \\
& $1: 5$ & $626.40(3.58)$ & $1.20(2.68)$ & $220.35(9.78)$ & $6.96(4.94)$ \\
& $5: 1$ & $20.60(12.16)$ & $601.80(22.92)$ & $15.85(12.20)$ & $232.72(13.69)$ \\
& $1: 1$ & $296.40(54.61)$ & $1327.40(381.42)$ & $127.5848 .77)$ & $534.07(175.45)$ \\
& $1: 5$ & $629.40(10.71)$ & $1.00(1.41)$ & $240.93(24.20)$ & $3.87(3.54)$ & $17.45(15.68)$ \\
\hline
\end{tabular}

Note. $\mathrm{COD}=$ Changeover Delay. Values are means from last five sessions of each phase. Standard deviations are shown in parentheses. Visit durations are in seconds. 
Table 3

Order of conditions for each subject in Experiment 2

\begin{tabular}{cccc} 
Subject & Ratio (color 1/color2) & Sessions & Order \\
\hline \hline 2748 & $60 / 60$ & 39 & 1 \\
& $50 / 70$ & 65 & 2 \\
& $100 / 20$ & 46 & 3 \\
3181 & $60 / 60$ & 40 & 1 \\
& $50 / 70$ & 43 & 2 \\
4079 & $100 / 20$ & 60 & 3 \\
& $60 / 60$ & 40 & 1 \\
795 & $100 / 20$ & 65 & 2 \\
& $50 / 70$ & 45 & 3 \\
& $60 / 60$ & 52 & 1 \\
9553 & $70 / 50$ & 56 & 2 \\
& $20 / 100$ & 55 & 3 \\
& $60 / 60$ & 69 & 1 \\
& $20 / 100$ & 41 & 2 \\
& $70 / 50$ & 36 & 3 \\
\hline
\end{tabular}

Note: Ratios shown were in effect for both variable-ratio and fixed-ratio schedules. Color 1 and color 2 were red and green for variable-ratio schedules and blue and orange for fixed-ratio schedules, respectively. 


\begin{tabular}{|c|c|c|c|c|c|}
\hline \multicolumn{6}{|l|}{$\begin{array}{l}\text { Table } 4 \\
\text { Mean run }\end{array}$} \\
\hline Subject & Reinforcer Ratio & Red Key & Green Key & Orange Key & Blue Key \\
\hline \multirow[t]{3}{*}{2748} & $1: 1$ & $32.19(4.36)$ & $32.93(10.61)$ & $27.10(3.30)$ & $20.02(2.52)$ \\
\hline & $1: 1.4$ & $44.64(6.67)$ & $16.93(0.91)$ & $31.31(6.62)$ & $17.96(1.58)$ \\
\hline & $5: 1$ & -- & $189.08(11.88)$ & $25.45(8.69)$ & $275.24(173.25)$ \\
\hline \multirow[t]{3}{*}{3181} & $1: 1$ & $14.66(3.19)$ & $12.68(2.21)$ & $21.59(3.98)$ & $25.74(4.05)$ \\
\hline & $1: 1.4$ & $15.02(1.79)$ & $12.36(0.98)$ & $31.73(2.71)$ & $28.78(5.67)$ \\
\hline & $5: 1$ & $17.50(7.56)$ & $595.67(565.62)$ & $41.54(4.93)$ & $68.64(28.82)$ \\
\hline \multirow[t]{3}{*}{4079} & $1: 1$ & $34.43(12.58)$ & $25.53(6.51)$ & $30.65(4.22)$ & $33.27(8.56)$ \\
\hline & $5: 1$ & $18.05(3.57)$ & $201.50(77.28)$ & $13.47(2.45)$ & $17.50(3.70)$ \\
\hline & $1: 1.4$ & $120.60(73.54)$ & $18.89(4.93)$ & $29.92(5.87)$ & $36.58(3.62)$ \\
\hline \multirow[t]{3}{*}{795} & $1: 1$ & $14.08(1.92)$ & $11.58(0.91)$ & $21.37(4.65)$ & $32.70(3.22)$ \\
\hline & $1.4: 1$ & $12.24(1.17)$ & $15.40(0.93)$ & $36.63(11.06)$ & $36.44(3.80)$ \\
\hline & $1: 5$ & $987.19(473.63)$ & $25.33(--)$ & $54.61(11.79)$ & $23.44(7.83)$ \\
\hline \multirow[t]{3}{*}{9553} & $1: 1$ & $50.67(12.48)$ & $15.93(2.66)$ & $45.66(13.20)$ & $27.27(10.42)$ \\
\hline & $1: 5$ & $1227.50(17.68)$ & -- & $588.70(542.75)$ & $24.24(22.58)$ \\
\hline & $1.4: 1$ & $40.16(5.93)$ & $15.86(0.41)$ & $56.13(8.70)$ & $34.76(10.52)$ \\
\hline
\end{tabular}

Note. Run lengths were averaged across the last five sessions of each condition. Standard deviations appear in parentheses. Conditions with too little data to calculate a measure are shown with dashes. 


\begin{tabular}{|c|c|c|c|c|c|}
\hline \multicolumn{6}{|l|}{ Table 5} \\
\hline \multirow[b]{2}{*}{ Subject } & \multirow[b]{2}{*}{ Reinforcer Ratio } & \multicolumn{2}{|c|}{ Concurrent Variable-Ratio Schedule } & \multicolumn{2}{|c|}{ Concurrent Fixed-Ratio Schedule } \\
\hline & & Red Key & Green Key & Orange Key & Blue Key \\
\hline \multirow[t]{3}{*}{2748} & $1: 1$ & $7.22(7.34)$ & $7.34(1.33)$ & $6.87(1.02)$ & $5.48(0.68)$ \\
\hline & $1: 1.4$ & $8.37(1.41)$ & $4.74(0.22)$ & $6.73(1.25)$ & $4.32(0.31)$ \\
\hline & $5: 1$ & -- & $189.08(11.88)$ & $6.59(1.70)$ & $61.78(36.98)$ \\
\hline \multirow[t]{3}{*}{3181} & $1: 1$ & $5.90(1.03)$ & $6.45(0.73)$ & $7.36(0.90)$ & $9.00(0.98)$ \\
\hline & $1: 1.4$ & $5.57(0.45)$ & $5.29(0.50)$ & $11.48(2.91)$ & $11.02(3.17)$ \\
\hline & $5: 1$ & $8.64(3.31)$ & $262.92(256.62)$ & $11.38(1.29)$ & $22.41(8.76)$ \\
\hline \multirow[t]{3}{*}{4079} & $1: 1$ & $11.52(3.55)$ & $9.19(1.94)$ & $10.24(1.27)$ & $11.29(3.00)$ \\
\hline & $5: 1$ & $6.79(1.42)$ & $77.24(25.73)$ & $8.15(1.22)$ & $17.19(6.22)$ \\
\hline & $1: 1.4$ & $40.80(23.41)$ & $7.82(1.47)$ & $16.94(6.07)$ & $15.04(0.44)$ \\
\hline \multirow[t]{3}{*}{795} & $1: 1$ & $9.66(1.47)$ & $8.42(0.77)$ & $13.94(2.18)$ & $16.06(1.69)$ \\
\hline & $1.4: 1$ & $8.88(1.07)$ & $10.85(0.15)$ & $18.56(7.16)$ & $17.50(2.37)$ \\
\hline & $1: 5$ & $555.50(259.30)$ & $19.44(--)$ & $25.87(4.83)$ & $9.20(1.92)$ \\
\hline \multirow[t]{3}{*}{9553} & $1: 1$ & $12.09(2.38)$ & $5.76(0.60)$ & $8.67(2.48)$ & $7.32(2.26)$ \\
\hline & $1: 5$ & $285.40(6.33)$ & -- & $136.57(122.63)$ & $8.41(5.27)$ \\
\hline & $1.4: 1$ & $9.45(1.36)$ & $5.64(0.15)$ & $11.55(2.06)$ & $8.34(1.78)$ \\
\hline
\end{tabular}

Note. Visit durations were averaged across the last five sessions of each condition. Durations are shown in seconds. Standard deviations appear in parentheses. Conditions with too little data to calculate a measure are shown with dashes. 
Table 6

Order of conditions for each subject in Experiment 3

\begin{tabular}{ccccc} 
Subject & $\begin{array}{c}\text { Reinforcers } \\
\text { per session } \\
\text { (red/green) }\end{array}$ & VR (red/green) & Sessions & Order \\
\hline \hline 11829 & $30 / 30$ & $30 / 30$ & 26 & 1 \\
& $39 / 21$ & $30 / 30$ & 39 & 2 \\
& $9 / 51$ & $30 / 30$ & 32 & 3 \\
11993 & $51 / 9$ & $30 / 30$ & 15 & 4 \\
& $30 / 30$ & $30 / 30$ & 26 & 1 \\
& $30 / 30$ & $50 / 10$ & 34 & 2 \\
13719 & $30 / 30$ & $10 / 50$ & 28 & 3 \\
& $30 / 30$ & $35 / 25$ & 24 & 4 \\
& $30 / 30$ & $30 / 30$ & 19 & 1 \\
& $30 / 30$ & $10 / 50$ & 33 & 2 \\
& $30 / 30$ & $25 / 35$ & 28 & 3 \\
\hline
\end{tabular}

Note $: V R=$ variable-ratio . 


\begin{tabular}{lccccc}
\hline \multicolumn{2}{l}{$\begin{array}{l}\text { Table } 7 \\
\text { Mean run lengths and visit durations on both response alternatives for all conditions of Experiment 3. } \\
\end{array}$} & \multicolumn{2}{c}{ Mean Run Length } & \multicolumn{2}{c}{ Mean Visit Duration } \\
Subject & Reinforcer Ratio & Red Key & Green Key & Red Key & Green Key \\
\hline \hline 11829 & $1: 1$ & $10.30(2.32)$ & $11.88(0.89)$ & $7.27(1.25)$ & $7.43(0.30)$ \\
& $1: 1.8$ & $13.73(2.29)$ & $8.65(0.55)$ & $9.57(1.98)$ & $6.39(0.71)$ \\
& $5.6: 1$ & $7.04(0.48)$ & $38.30(4.09)$ & $6.40(0.35)$ & $18.97(2.41)$ \\
& $1: 5.6$ & $28.05(4.16)$ & $7.17(0.55)$ & $17.62(2.56)$ & $5.06(0.50)$ \\
\hline 11993 & $1: 1$ & $28.15(2.87)$ & $26.30(3.49)$ & $8.51(0.64)$ & $8.60(0.59)$ \\
& $1.4: 1$ & $21.66(3.60)$ & $19.89(1.19)$ & $6.64(0.55)$ & $6.28(0.44)$ \\
& $1: 5$ & $16.78(1.23)$ & $29.40(4.48)$ & $6.34(0.59)$ & $7.67(0.82)$ \\
& $5: 1$ & $22.27(1.60)$ & $27.41(2.67)$ & $6.86(0.37)$ & $7.54(0.71)$ \\
\hline 13719 & $1: 1$ & $20.50(4.43)$ & $18.04(2.01)$ & $7.64(1.14)$ & $6.91(0.81)$ \\
& $1.4: 1$ & $19.68(1.53)$ & $19.75(2.46)$ & $7.32(0.57)$ & $7.23(0.91)$ \\
& $1: 5$ & $17.05(0.58)$ & $15.54(1.04)$ & $8.02(0.28)$ & $6.69(2.02)$ \\
\end{tabular}

Note. $\mathrm{COD}=$ Changeover Delay. Values are means from last five sessions of each phase. Standard deviations are shown in parentheses. Visit durations are in seconds. 


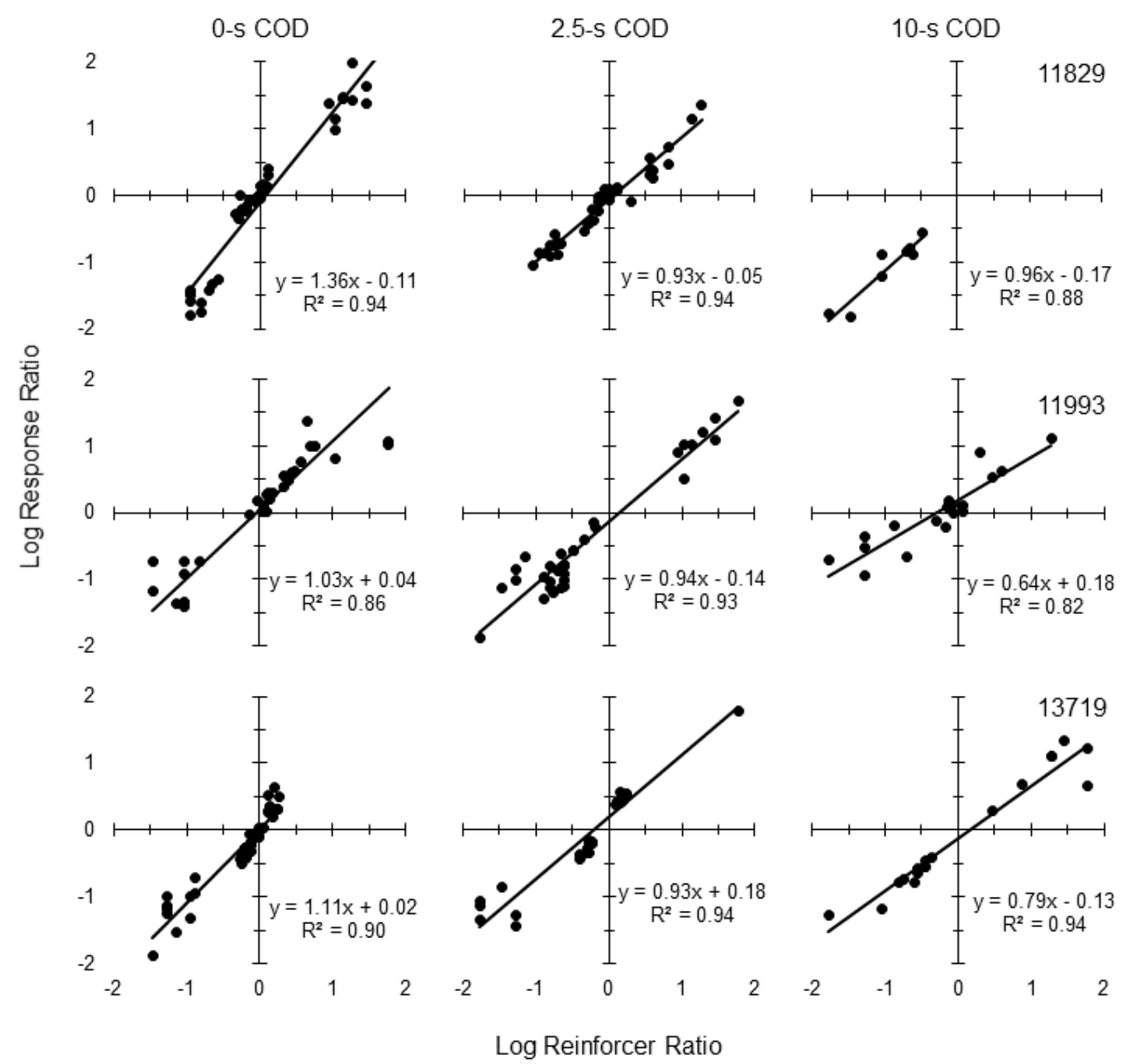

Figure 1. Log response ratios shown as a function of log reinforcer ratios. Data points are response ratios calculated from a single session. Data are shown for the last 10 sessions of each phase in a condition. Solid lines and accompanying equations show the best fits of Equation 1. 


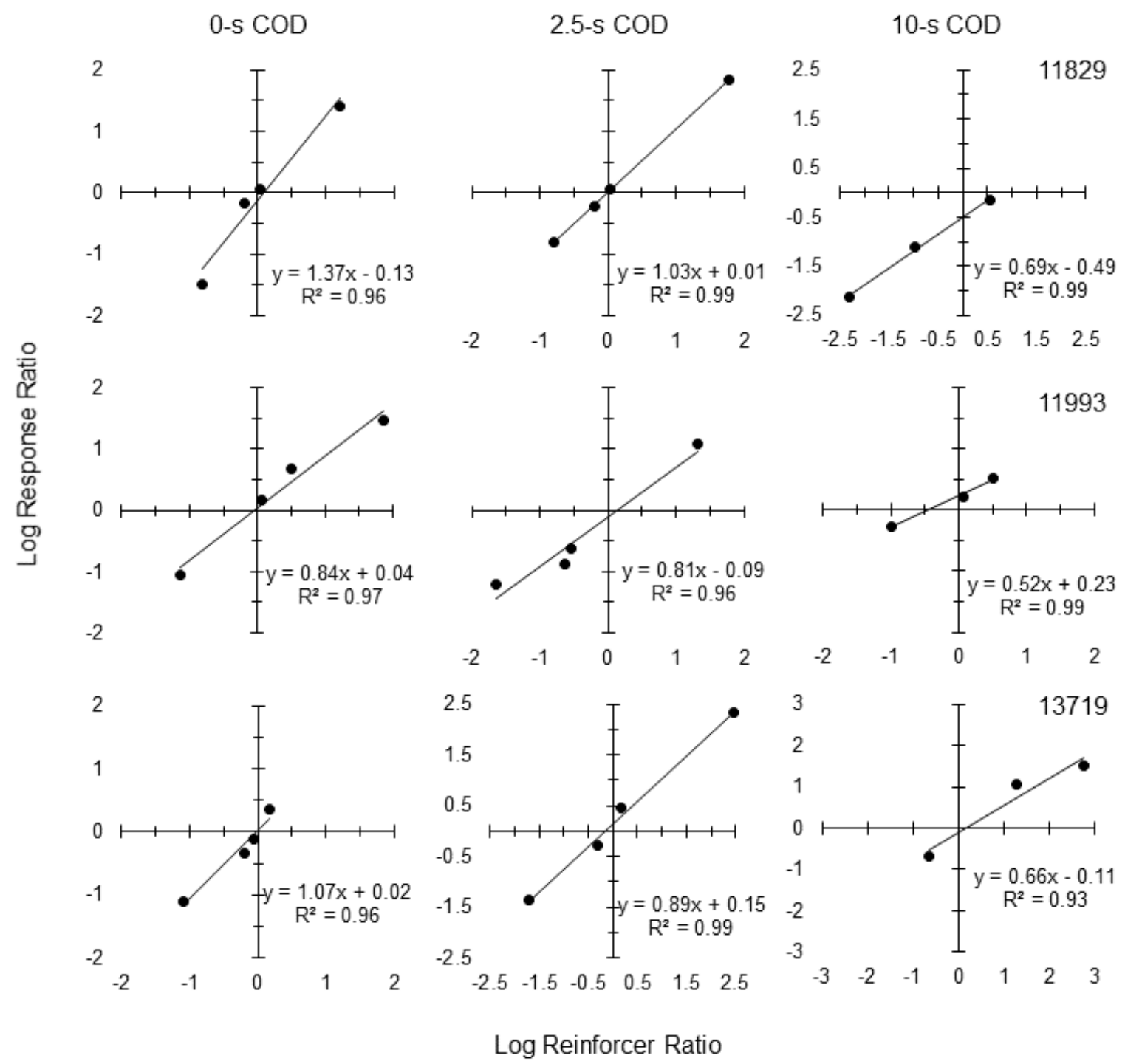

Figure 2. Log response ratios shown as a function of log reinforcer ratios. Data points are response ratios calculated by summing all responses from the last 10 session of each phase. Solid lines and accompanying equations show the best fits of Equation 1. 


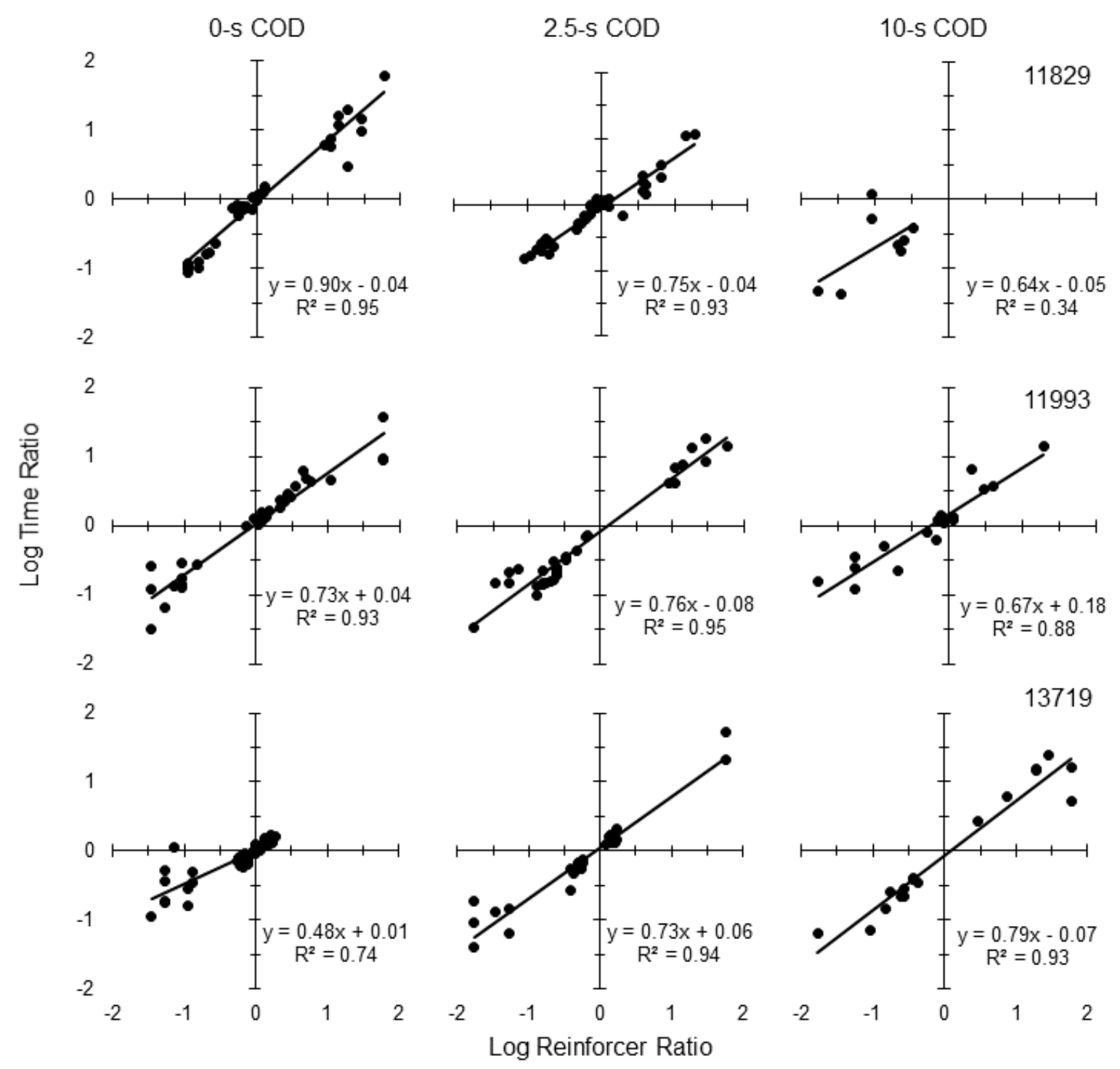

Figure 3. Log time ratios shown as a function of $\log$ reinforcer ratios. Data points are time ratios calculated from a single session. Data are shown for the last 10 sessions of each phase in a condition. Solid lines and accompanying equations show the best fits of Equation 1. 

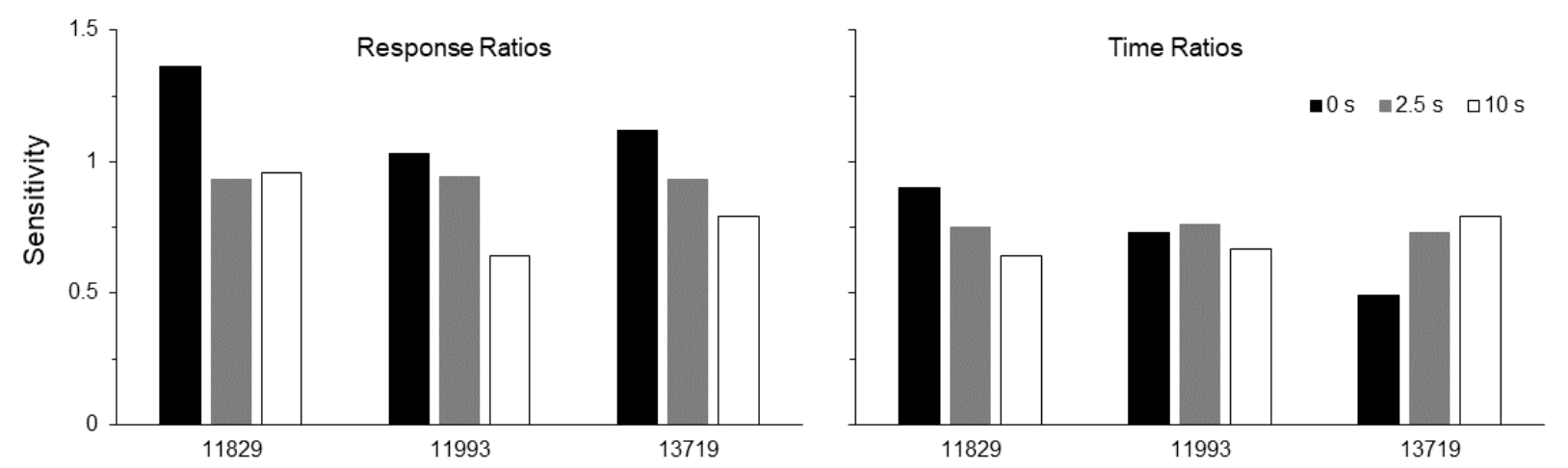

Figure 4. Sensitivity estimates calculated by fitting Equation 1 to response ratios (left) and time ratios (right). Data are shown for each condition with different changeover-delays across all pigeons. 

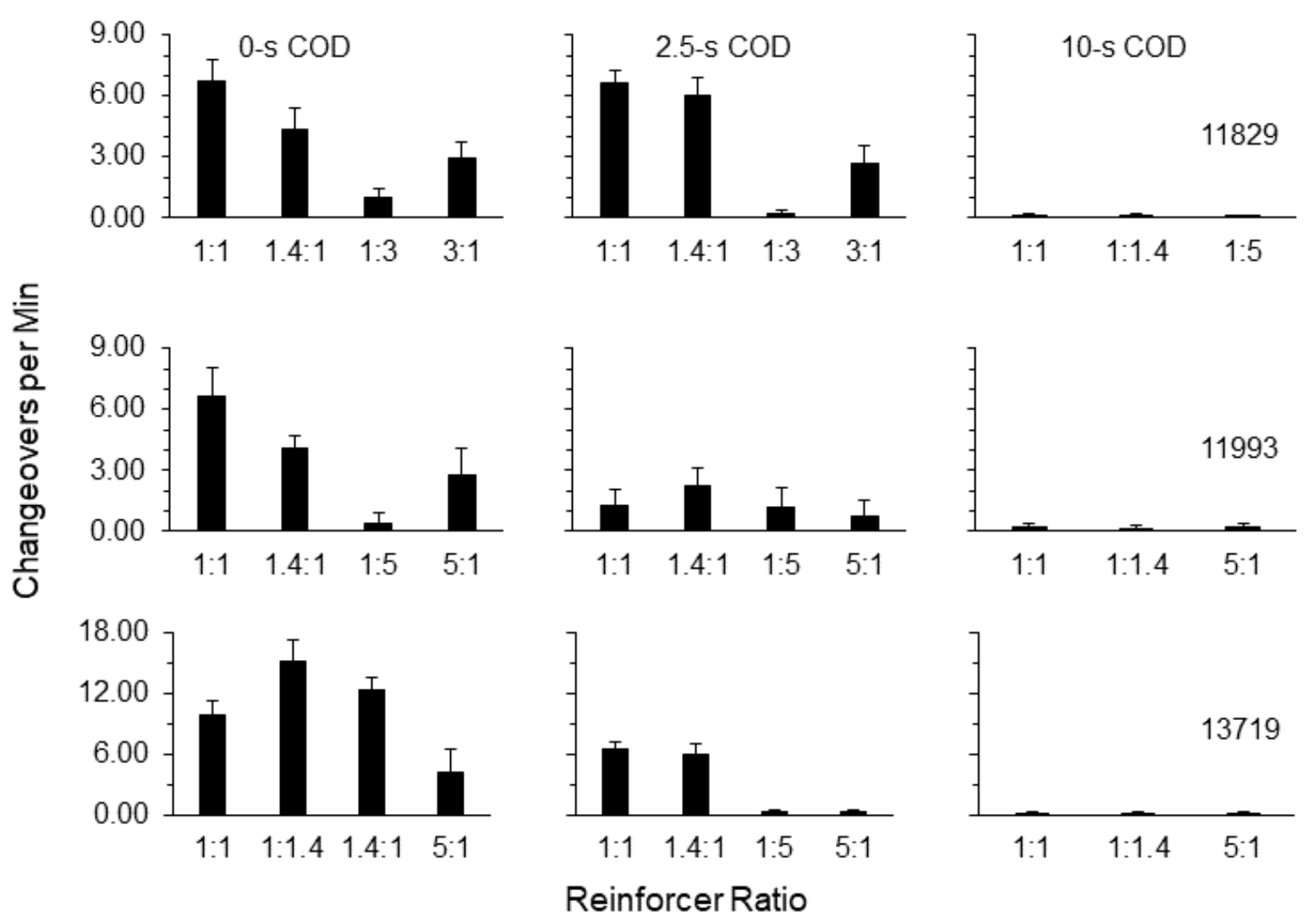

Figure 5. Changeover rate (changeovers per min) shown as a function of reinforcer ratios for all conditions across all pigeons. Reinforcer ratios were presented across phases within a condition. Means were calculated from the last 10 sessions of each phase. Error bars represent standard deviations. 


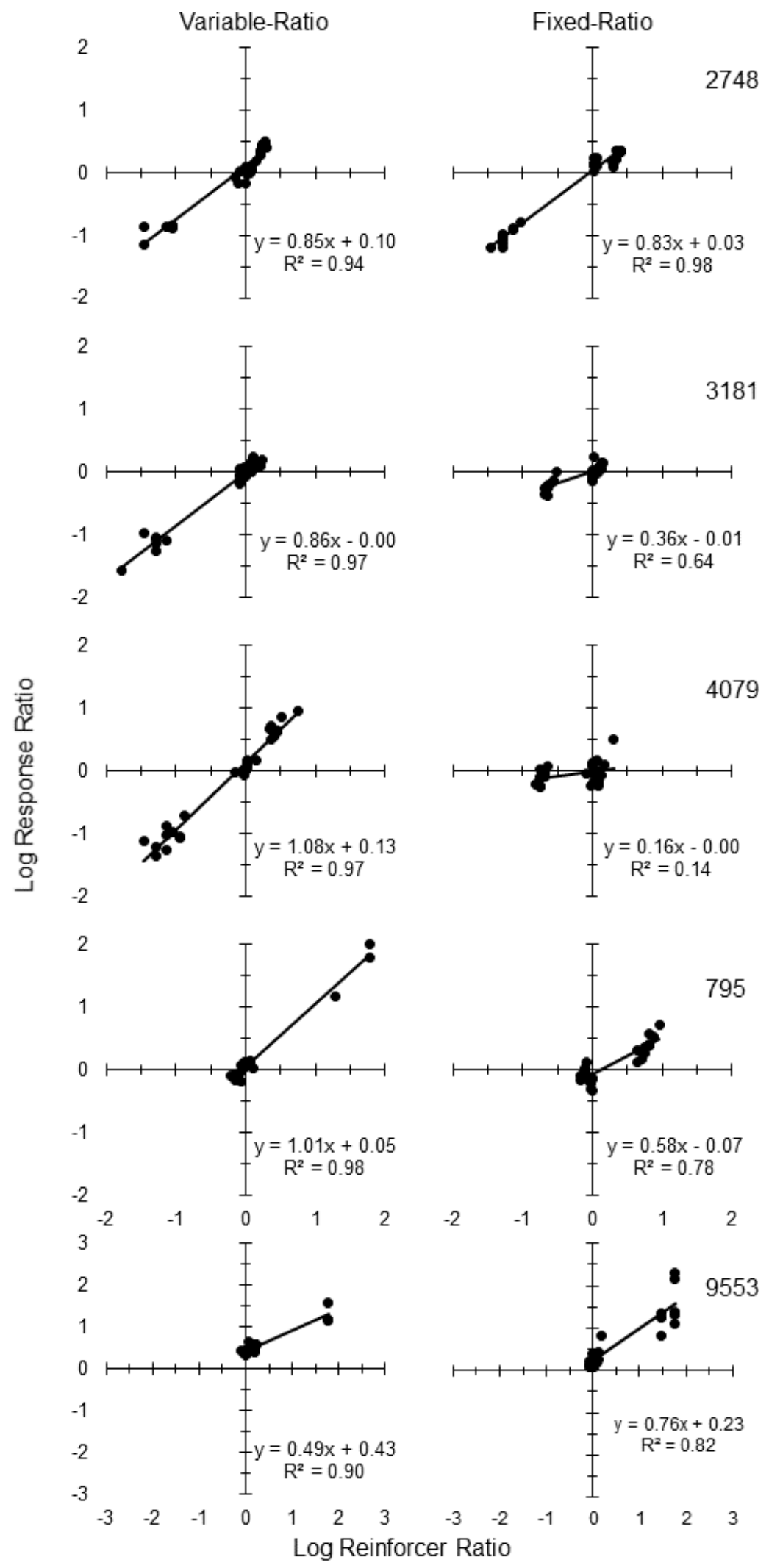


Figure 6. Log response ratios shown as a function of log reinforcer ratios. Data points are response ratios calculated from a single session. Ratios were calculated separately for VR and FR sessions. Data are shown for the last 10 sessions of each condition. Solid lines and accompanying equations show the best fits of Equation 1. 


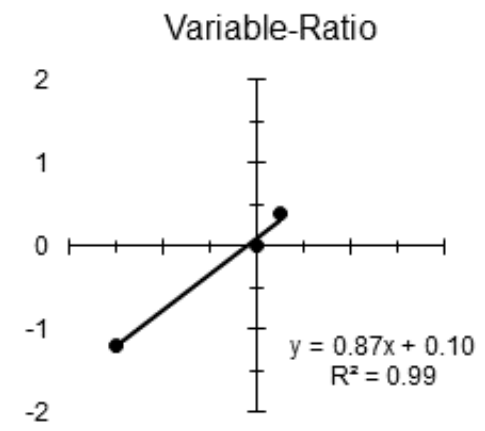

Fixed-Ratio
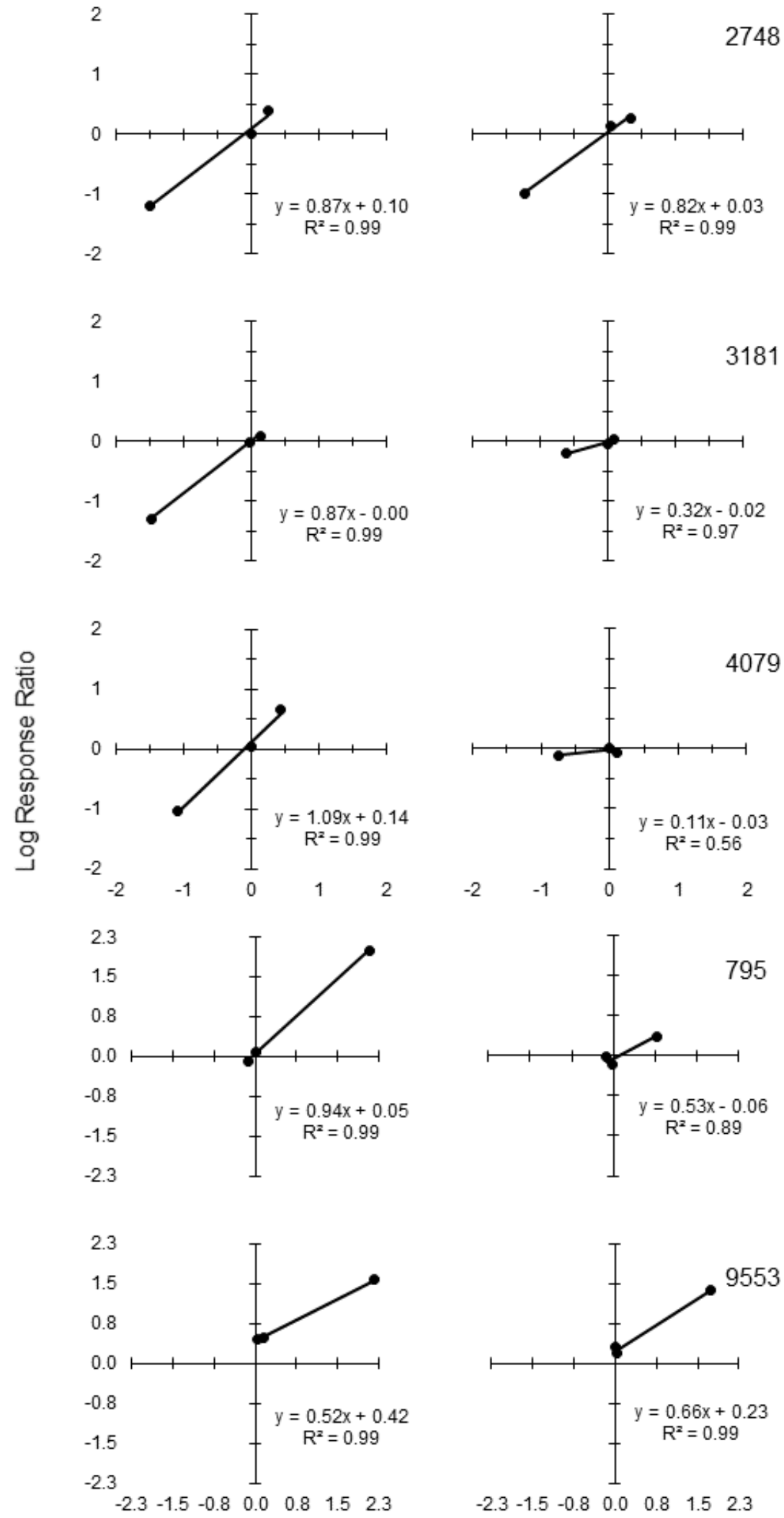

Log Reinforcer Ratio 
Figure 7. Log response ratios shown as a function of log reinforcer ratios. Data points are response ratios calculated by summed responses from the last 10 sessions of each condition. Ratios were calculated separately for VR and FR sessions. Solid lines and accompanying equations show the best fits of Equation 1. 


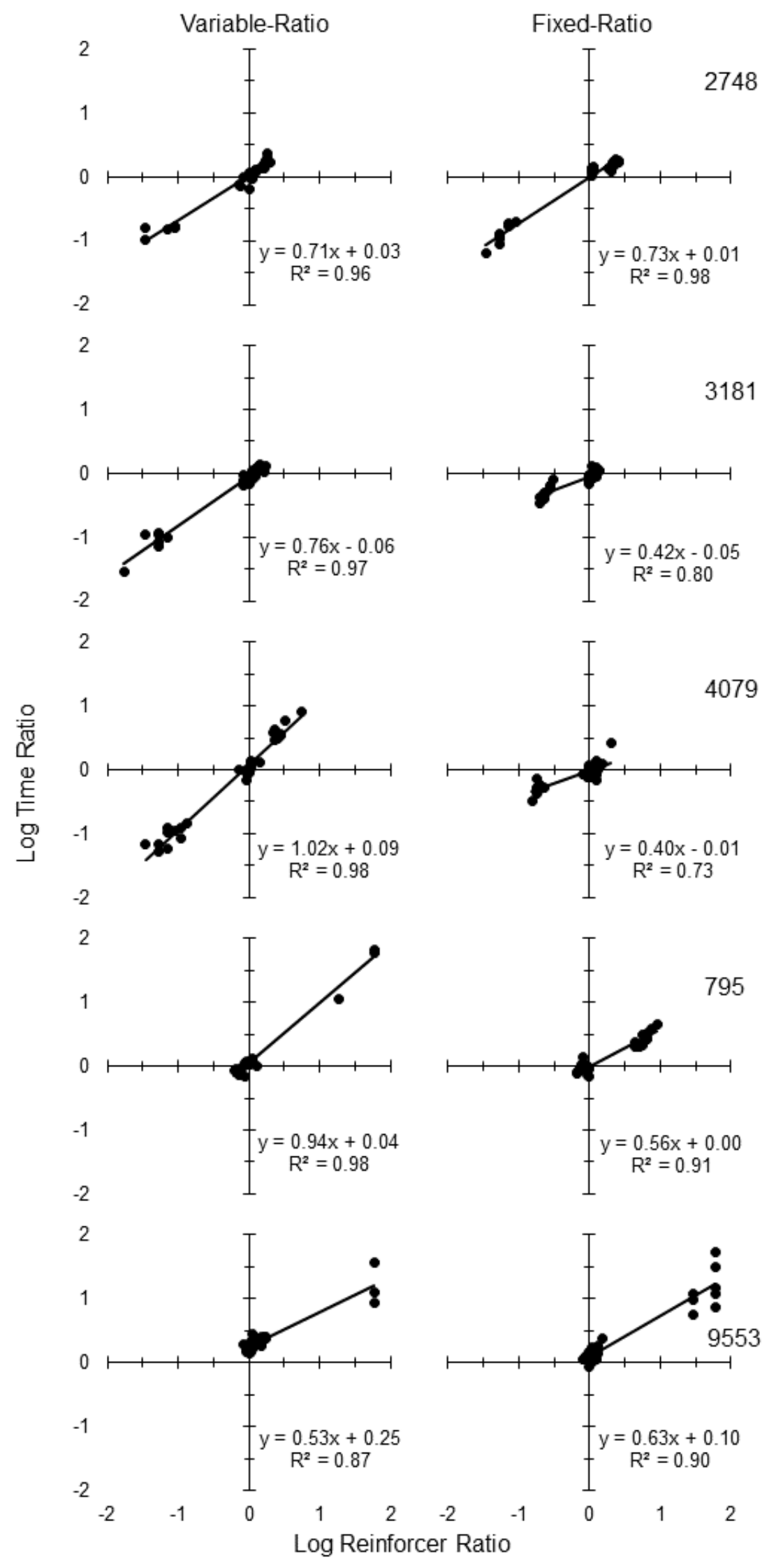


Figure 8. Log time ratios shown as a function of $\log$ reinforcer ratios. Data points are time ratios calculated from a single session. Ratios were calculated separately for VR and FR sessions. Data are shown for the last 10 sessions of each condition. Solid lines and accompanying equations show the best fits of Equation 1. 

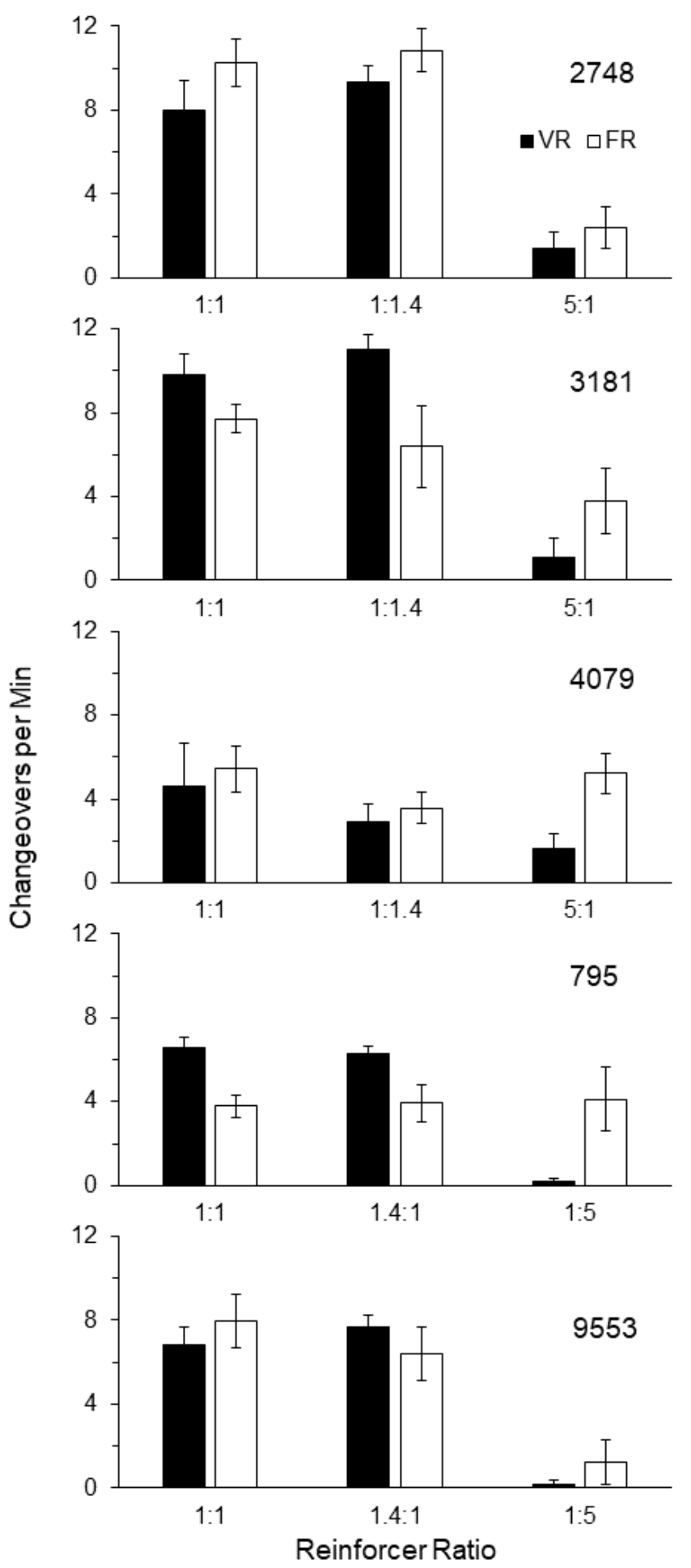

Figure 9. Changeover rate (changeovers per min) shown as a function of reinforcer ratios for all pigeons. Means were calculated from the last 10 sessions of each condition separately for VR and FR sessions. Error bars represent standard deviations. 

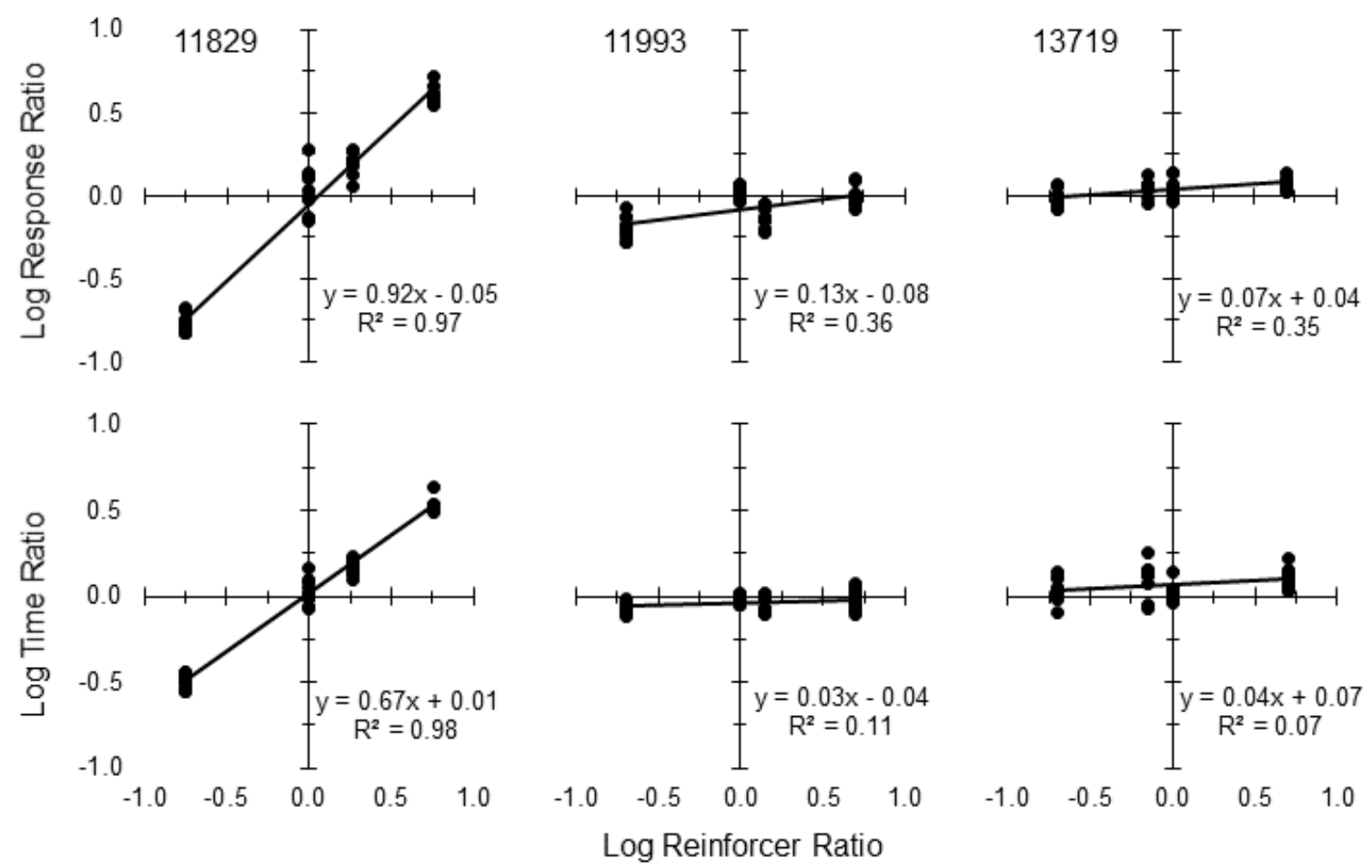

Figure 10. Log response ratios shown as a function of log reinforcer ratios. Data points are response ratios calculated from a single session. Reinforcer ratios for Pigeon 11829 were the number of reinforcers delivered from the red key divided by the number delivered from the green key. Reinforcer ratios for Pigeons 11993 and 13719 were the VR value on the red key divided by the value on the green key. Data are shown for the last 10 sessions of each condition. Solid lines and accompanying equations show the best fits of Equation 1 . 


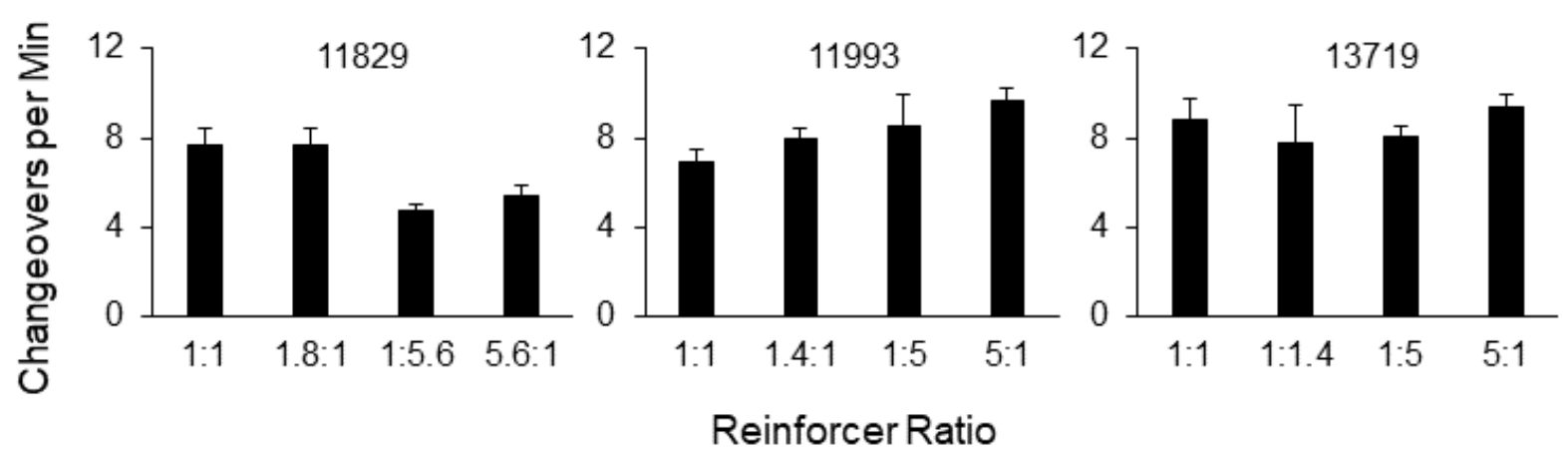

Figure 11. Changeover rate (changeovers per min) shown as a function of reinforcer ratios for all pigeons. Means were calculated from the last 10 sessions of each condition. Error bars represent standard deviations. 